\title{
Flow regime transition criteria for two-phase flow at reduced gravity conditions
}

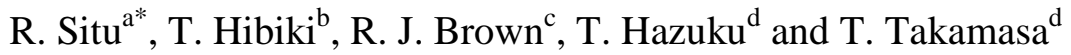

a School of Engineering and Physical Sciences, James Cook University, Townsville, QLD 4811, Australia.

${ }^{\mathrm{b}}$ School of Nuclear Engineering, Purdue University, 400 Central Drive, West Lafayette, IN 47907-2017, USA.

${ }^{c}$ Faculty of Built Environment and Engineering, Queensland University of Technology, 2 George Street, Brisbane, QLD 4001, Australia.

d Graduate School of Marine Science and Technology, Tokyo University of Marine Science and Technology, 2-1-6 Etsujima, Koto 135-8533, Tokyo, Japan.

*Corresponding author: Tel: +61-7-47814172, Fax: +61-7-47816788, Email: rong.situ@jcu.edu.au 


\begin{abstract}
Flow regime transition criteria are of practical importance for two-phase flow analyses at reduced gravity conditions. Here, flow regime transition criteria which take the frictional pressure loss effect into account were studied in detail. Criteria at reduced gravity conditions were developed by extending an existing model from normal gravity to reduced gravity conditions. A comparison of the newly developed flow regime transition criteria model with various experimental datasets taken at microgravity conditions showed satisfactory agreement. Sample computations of the model were performed at various gravity conditions, such as $0.196,1.62,3.71$ and $9.81 \mathrm{~m} / \mathrm{s}^{2}$ corresponding to micro-gravity and lunar, Martian and Earth surface gravity, respectively. It was found that the effect of gravity on bubbly-slug and slug-annular (churn) transitions in a twophase flow system was more pronounced at low liquid flow conditions, whereas the gravity effect could be ignored at high mixture volumetric flux conditions. While for the annular flow transitions due to flow reversal and onset of droplet entrainment, higher superficial gas velocity was obtained at higher gravity level.
\end{abstract}

Keywords: Flow regime; Transition; Reduced gravity; Microgravity; Multiphase flow; Two-phase flow. 


\section{Introduction}

With the advent of modern cooling systems, the increasing demand to meet stringent weight- and space-saving design parameters for large spacecraft such as the International Space Station requires extensive heat removal to ensure acceptable internal environmental conditions. This cannot be accomplished by conventional single-phase forced or natural convection flows. Hence two-phase thermal systems have been developed with forced convective boiling flows which have a controllable heated surface temperature to yield a relatively high heat transfer coefficient and the possibility of meeting compact space requirements (Grigoriev et al., 1996). In view of the great importance of this to the thermal-hydraulic design of thermal-control systems at reduced gravity conditions, a number of experiments have been performed for two-phase flow at reduced gravity conditions by means of a drop tower or an aircraft (Heppner et al., 1975; Dukler et al., 1988; Colin et al., 1991; Zhao and Rezkallah, 1993; Bousman et al., 1996; Choi et al., 2003; Takamasa et al., 2003, 2004). In these experiments, the measured essential two-phase flow characteristics included flow regime, void fraction, and interfacial area concentration.

The internal structures of the two-phase flow are classified by the flow regimes or flow patterns. Transfer mechanisms between the two-phase mixture and the wall, as well as between the phases, depend on the flow regimes. This leads to the use of regimedependent correlations together with two-phase flow regime criteria. The basic structure of the two-phase flow can also be characterized by two fundamental geometrical parameters: void fraction and interfacial area concentration. The former expresses the phase distribution and is a required parameter for both the drift-flux model, one of the most practical and accurate models for hydrodynamic and thermal design in various industrial processes, and the two-fluid model, which describes in detail the thermal-hydraulic transients and phase interactions. In the two-fluid model, the main difficulties arise from the existence of interfaces between the phases and the associated discontinuities. Hence interfacial area was introduced to describe the available area for the interfacial transfer of mass, momentum and energy, which is modeled in the interfacial area transport model, a crucial complement of the two-fluid model. 
The application of the drift-flux and two-fluid models as well as of the interfacial area transport equation in reduced gravity conditions has enjoyed great success recently. In the drift-flux model, the constitutive equations of the distribution parameter for bubbly flow, which takes the gravity effect into account, have been proposed. The constitutive equations for slug, churn and annular flows, which can be applicable to reduced gravity conditions, have also been recommended based on existing experimental and analytical studies. The second essential parameter, drift velocity, was modeled by taking frictional pressure loss into account in various flow regimes (Hibiki et al., 2006). On the other hand, the interfacial area transport equation was also extended to reduced gravity conditions. The constitutive equation for the sink term due to wake entrainment was formulated by considering body acceleration due to frictional pressure loss. The newly-developed interfacial area transport equation agreed satisfactorily with experimental data taken at normal and reduced gravity conditions (Hibiki et al., 2009).

In the thermal-hydraulic system analysis codes developed in a normal gravity environment, the effects of interfacial structure were analyzed by using models of flow regime transition criteria. Some of these models were extended to microgravity conditions with some success. For example, the model by Dukler et al. (1988), based on the critical void fraction at both bubbly-slug and slug-annular transitions, appeared to agree well with the experimental data. Lee et al. (1987) suggested that the bubbly-slug transition happens when the force of eddy turbulent fluctuation is greater than the surface tension force, and slug-annular transition occurs when the inertial force is greater than the surface tension force. The latter criterion led to the Weber number based model proposed by Rezkallah and his colleagues (Zhao and Rezkallah, 1993; Rezkallah and Zhao, 1995; Rezkallah, 1996; Lowe and Rezkallah, 1999). However, the Dukler et al. model depends on the estimation of the area-averaged void fraction, $\alpha$, which has to be adjusted to fit for different fluids and pipe sizes (Bousman et al., 1996; Zhao and Rezkallah, 1993). Moreover, few churn flow in microgravity conditions has been reported. Instead, models of slug-annular transition have been proposed to cover this broad range. Most importantly, no general models on various gravity levels, such as the lunar and Martian levels, exist. 
Acknowledging the importance of the flow regime transition criteria models under reduced gravity conditions, this study presents an extensive survey of existing models and data at reduced gravity conditions, and extends the well-established Mishima and Ishii (M-I) model at normal gravity conditions (Mishima and Ishii, 1984) to reduced gravity conditions. The proposed model with its large datasets of different fluid property and pipe sizes is also evaluated. Furthermore, a feasibility study is performed to apply the new model to other gravity conditions such as the lunar and Martian gravity levels.

\section{Literature survey}

2.1 Existing data of the flow regime transition boundary in two-phase flow at reduced gravity conditions

Table 1 summarizes the experimental investigations of the two-phase flow regime under microgravity conditions that have been performed since the 1970s (Heppner et al., 1975). Most of the experiments were conducted on parabolic flights such as in KC-135, MU-300, Learjet and IL-76, since they could provide about $20 \mathrm{~s}$ of microgravity conditions. Dukler et al. (1988) performed the tests in a 30-m drop tower, with only $2.2 \mathrm{~s}$ of reduced gravity. The best environment is space and an experiment was performed by Zhao et al. (2001a) on board the Russian space station MIR. In addition, a few tests attempted to use two immiscible liquids with near equal densities (Karri and Mathur, 1988; Vasavada et al., 2007) or capillary tubes (Galbiati and Andreini, 1994) under normal gravity to simulate microgravity conditions. According to Brauner (1990), the criterion for a capillary tube system to be an equivalent microgravity system is Bond number $B o \equiv \frac{\Delta \rho g_{\mathrm{G}} D^{2}}{\sigma}<6$, where $\Delta \rho$ is the density difference between phases, $g_{\mathrm{G}}$ is the gravitational body acceleration $\left(=9.81 \mathrm{~m} / \mathrm{s}^{2}\right.$ on the Earth's surface, and $0 \mathrm{~m} / \mathrm{s}^{2}$ at zero gravity), $D$ is the pipe diameter, and $\sigma$ is the surface tension. The Bond number in Galbiati and Andreini's capillary tube experiment is around 0.13 , which is in the microgravity range.

Both adiabatic (non-boiling) and diabatic (boiling) datasets are available in the literature. For adiabatic flow, the majority of the research has used air-water systems, including round tube (Colin and Fabre, 1995; Huckerby and Rezkallah, 1992) and square channel (Zhao et al., 2001b). Other investigators used water/glycerin to study the effect 
of liquid viscosity (Rite, 1995), and water/Zonyl FSP (Bousman et al., 1996) and carbogal (Zhao et al., 2001a) to study surface tension. As for boiling experiments, studies have been performed using water (Kachnik et al., 1987) and refrigerants such as R11 (Crowley and Sam, 1991), R114 (Hill et al., 1987) and R12 (Hill and Best, 1991; Valota et al., 2007).

Of the four basic flow regimes under normal gravity, i.e. bubbly (B), slug (S), annular (A) and churn (C), the first three have been mostly observed at microgravity conditions. In addition, Fujii et al. (1995) and Choi et al. (2003), conducting horizontal flow under microgravity conditions, reported plug (Taylor bubble) flow (P), which has smooth-nose bubbles, and liquid slug without small bubbles. For churn flow, which has oscillating gas and liquid slug, only two findings have been reported under microgravity (Rite and Rezkallah, 1997). A global consensus of the classification of these two records into churn flow has not been fully achieved, because no gravity effect would force liquid slug to flow downwards.

Nevertheless, Hill et al. (1987) found that the transition between slug flow and annular flow has increasingly rough liquid surface and droplet mist, similar to churn flow in vertical up-flow, but without the observation of flow reversal. Hill et al. (1987) found another new flow regime: "frothy annular", with thick annular liquid film containing vapor phase content. Similarly, Zhao and Rezkallah (1993) defined the flow regime between slug and annular as "frothy slug-annular" (FSA), with frothy slug frequently appearing in the gas phase in the center and annular liquid film at the tube wall. This regime was also reported by Lowe and Rezkallah (1999), Zhao et al. (2001a) and Valota et al. (2007) as transitional flow (T). It should be noted that the determination of these flow types was very subjective, and not accurate enough to distinguish this flow type from annular flow type. So they can be grouped together with annular flow regime, and then only three main flow regimes, bubbly, slug, and annular (churn) flow, exist under microgravity conditions.

2.2 Existing models of flow regime transition criteria in two-phase flow at reduced gravity conditions 
Modeling of two-phase flow regime transition at reduced gravity has been developed along with the construction of microgravity databases (Zhao and $\mathrm{Hu}, 2000$ ). Proposed models in the literature include a void fraction based model (Dukler et al., 1988), a force balance based model (Lee et al., 1987), a Weber number based model (Zhao and Rezkallah, 1993), and a dimensionless number model (Jayawardena et al., 1997).

Dukler et al. (1988) assumed that at bubbly-slug transition, liquid velocity equals gas velocity, and adjacent bubbles contact each other, which gives a void fraction of 0.45 , and

$$
j_{\mathrm{f}}=1.22 j_{\mathrm{g}}
$$

where $j_{\mathrm{f}}$ and $j_{\mathrm{g}}$ are superficial liquid velocity and superficial gas velocity respectively. Similarly, Colin et al. (1991) and Zhao and Rezkallah (1993) empirically determined the critical void fraction to be 0.20 and 0.18 , respectively, with the assumption of zero drift velocity giving

$$
j_{\mathrm{f}}=3.2 j_{\mathrm{g}},
$$

and

$$
j_{\mathrm{f}}=4.56 j_{\mathrm{g}} \text {. }
$$

For the slug-annular transition criteria, Dukler et al. (1988) equated the areaaveraged void fraction in slug flow (estimated from the distribution parameter $C_{0}$ in the drift-flux model) with that in annular flow (estimated based on force balance on the liquid film). Similarly, Lee et al. (1987) conducted theoretical force balance analysis on four basic horizontal flow patterns: dispersed, slug, stratified and annular. They claimed that transition from other flow to stratified flow occurs when body force overcomes surface tension (superficial liquid velocity less than $0.01 \mathrm{~m} / \mathrm{s}$ ), transition from slug to dispersed flow occurs when eddy turbulent fluctuation is higher than surface tension, and transition from slug to annular takes place if inertial force dominates surface tension. The last criterion was also deduced for the Weber number model (Zhao and Rezkallah, 1993), since the Weber number is the ratio of inertial force over surface tension. According to Zhao and Rezkallah (1993), the transition from slug to FSA occurs at

$$
W e_{\mathrm{sg}} \equiv \frac{\rho_{\mathrm{g}} j_{\mathrm{g}}^{2} D}{\sigma}=1
$$


where $\rho_{\mathrm{g}}$ is the gas density. The transition from FSA to annular happens at

$$
W e_{\mathrm{sg}}=20 \text {, }
$$

Similarly, other investigators (Jayawardena et al., 1997) attempted to find transition lines on a flow pattern map using a dimensionless number such as a Suratman number $\left(S u \equiv R \mathrm{e}_{\mathrm{sf}}{ }^{2} / W e_{\mathrm{sf}}\right)$ as well as gas and liquid Reynolds numbers:

$$
\begin{gathered}
\text { Bubbly-slug transition: } \frac{R e_{\mathrm{sg}}}{R e_{\mathrm{sf}}}=464.16 \mathrm{Su}^{-2 / 3}, \text { when } 10^{4}<S u<10^{7} \\
\text { Slug-annular transition: } \frac{R e_{\mathrm{sg}}}{R e_{\mathrm{sf}}}=4641.6 \mathrm{Su} u^{-2 / 3}, \text { for } \mathrm{Su}<10^{6} \\
\qquad e_{\mathrm{sg}}=2 \times 10^{-9} \mathrm{Su}^{2}, \quad \text { for } \mathrm{Su}>10^{6}
\end{gathered}
$$

where gas and liquid Reynolds numbers are defined as $R \mathrm{e}_{\mathrm{sf}} \equiv \rho_{\mathrm{f}} j_{\mathrm{f}} D / \mu_{\mathrm{f}}$ and $R \mathrm{e}_{\mathrm{sg}} \equiv \rho_{\mathrm{g}} j_{\mathrm{g}} D / j_{\mathrm{g}}$, respectively.

\section{Modeling of flow regime transition criteria in two-phase flow at reduced gravity conditions}

\subsection{Body acceleration due to the frictional pressure drop}

Under microgravity conditions, the gravity force which pushes a gas phase faster than a liquid phase becomes negligible. This major difference between microgravity and normal gravity led to the assumption adopted by some researchers that there was no local slip between bubble and liquid. However, Tomiyama et al. (1998) found through theoretical analysis that the relative velocity between a single bubble and liquid flow in a confined channel exists and is driven by a frictional pressure gradient due to a liquid flow. This was confirmed by bubbly flow experiments at low liquid Reynolds numbers (Takamasa et al., 2004). This single particle system was extended to a multiple-particle system, where the actual body acceleration, $g_{\mathrm{B}}$, on the gas phase consists of the body acceleration due to the frictional pressure drop at the wall, $g_{\mathrm{F}}$ (Hibiki and Ishii, 2003):

$$
g_{\mathrm{B}}=g_{\mathrm{G}}+g_{\mathrm{F}}=g_{\mathrm{G}}+\frac{M_{\mathrm{F}}}{\Delta \rho(1-\alpha)},
$$

where $\alpha$ is the area-averaged void fraction, and $M_{\mathrm{F}}$ is the frictional pressure gradient in a multi-particle system, given by 


$$
M_{\mathrm{F}} \equiv\left(-\frac{\mathrm{d} p}{\mathrm{~d} z}\right)=\Phi_{\mathrm{f}}^{2} M_{\mathrm{F} \infty}
$$

where $\Phi_{\mathrm{f}}^{2}$ is the two-phase multiplier calculated by Lockhart-Martinelli's (1949) correlation, and $M_{\mathrm{F} \infty}$ is the frictional pressure gradient in a confined channel flow with a single bubble, approximated by

$$
M_{\mathrm{F} \infty}=\frac{f}{2 D} \rho_{\mathrm{f}} v_{\mathrm{f}}^{2},
$$

where $f$ is the wall friction factor.

Recently, the relative motion between gas and liquid phases has been successfully modeled by taking into account the effect of a frictional pressure gradient caused by a liquid flow (Hibiki et al. 2006):

Bubbly flow

$$
V_{g j}=\sqrt{2}\left[\frac{\left(\Delta \rho g_{\mathrm{G}}+M_{\mathrm{F} \infty}\right) \sigma}{\rho_{\mathrm{f}}^{2}}\right]^{1 / 4} \times \frac{18.67(1-\alpha)^{2}\left[\frac{\Delta \rho g_{\mathrm{G}}(1-\alpha)+M_{\mathrm{F}}}{\Delta \rho g_{\mathrm{G}}+M_{\mathrm{F} \infty}}\right]}{1+17.67(1-\alpha)^{6 / 7}\left[\frac{\Delta \rho g_{\mathrm{G}}(1-\alpha)+M_{\mathrm{F}}}{\Delta \rho g_{\mathrm{G}}+M_{\mathrm{F} \infty}}\right]^{3 / 7}},
$$

Slug flow

$$
V_{\mathrm{gj}}=0.35\left\{\frac{\left[\Delta \rho g_{\mathrm{G}}(1-\alpha)+M_{\mathrm{F}}\right] D}{\rho_{\mathrm{f}}(1-\alpha)}\right\}^{1 / 2},
$$

Churn flow

$$
V_{\mathrm{gj}}=\sqrt{2}\left\{\frac{\left[\Delta \rho g_{\mathrm{G}}(1-\alpha)+M_{\mathrm{F}}\right] \sigma}{\rho_{\mathrm{f}}^{2}}\right\}^{1 / 4},
$$

Annular flow

$$
V_{\mathrm{gj}} \approx 0 \text {. }
$$

where $V_{\mathrm{gj}}$ is the void-fraction weighted area-average drift velocity.

\subsection{Body acceleration considering frictional pressure loss in forced convective flow}

For a relatively high mixture-volumetric-flux condition, the actual body acceleration is much higher than the normal gravity acceleration. Figure 1 presents the ratio of actual body acceleration over gravitational body acceleration, $g_{\mathrm{B}} / g_{\mathrm{G}}$, versus the superficial gas 
velocity, $j_{\mathrm{g}}$, as a parameter of superficial liquid velocity, $j_{\mathrm{f}}$. According to the onedimensional drift flux model, the relationship between $j_{\mathrm{g}}$ and $j_{\mathrm{f}}$ is

$$
\frac{j_{\mathrm{g}}}{\alpha}=C_{0}\left(j_{\mathrm{g}}+j_{\mathrm{f}}\right)+V_{\mathrm{gj}},
$$

where $C_{0}$ and $V_{\mathrm{gj}}$ are calculated using equations by Hibiki and Ishii (2003). It is suggested in Fig. 1 that when $j_{\mathrm{g}}$ is less than $1 \mathrm{~m} / \mathrm{s}, g_{\mathrm{B}}$ is close to $g_{\mathrm{F}}$, while after $j_{\mathrm{g}}$ becomes higher than $1.0 \mathrm{~m} / \mathrm{s}, g_{\mathrm{B}}$ starts to grow as $j_{\mathrm{g}}$ increases. When $j_{\mathrm{f}}$ is far less than $1.0 \mathrm{~m} / \mathrm{s}, \mathrm{g}_{\mathrm{B}}$ only increases to $16 \%$ higher than $g_{\mathrm{G}}$ at $j_{\mathrm{g}}=5 \mathrm{~m} / \mathrm{s}$. Nevertheless for $j_{\mathrm{f}}=1.0 \mathrm{~m} / \mathrm{s}, g_{\mathrm{B}}$ can reach 2.8 times of $g_{\mathrm{G}}$ for $j_{\mathrm{g}}=5 \mathrm{~m} / \mathrm{s}$. When $j_{\mathrm{g}}$ grows further, void fraction will increase according to Eq. (15); so does $g_{\mathrm{B}}$, as indicated from Eq. (8).

\subsection{Extended Mishima-Ishii (M-I) model}

Under normal gravity, the M-I model has been successfully applied for a flow regime transition in vertical upward flow. In the M-I model, the transition from bubbly flow to slug flow was presumed to occur at an area-averaged void fraction of 0.3 . The slug flow to churn flow transition was postulated to occur when the mean void fraction of the entire region exceeded that of the slug-bubble section. For churn flow to annular flow transition, two mechanisms were proposed: (i) flow reversal in liquid film section, and (ii) the destruction of liquid slugs or large waves by entrainment or deformation.

The effect of body acceleration, which is important at reduced gravity conditions, was not considered in the M-I criteria. In following, the M-I model will be modified using body acceleration, taking account of the frictional pressure drop. The extended M-I criteria may be utilized to estimate the flow regime transition criteria at reduced gravity conditions.

Mishima and Ishii (1984) stated that the M-I model is applicable for air-water flow and steam-water flow under steady-state and fully-developed flow conditions. If the tube length is short, inlet flow condition would affect the final flow pattern. However, if the tube length is long enough, the flow regime in the fully-developed region can be predicted by the proposed model.

\subsubsection{Bubbly to slug flow transition}


Figure 2(a) shows a schematic diagram of bubbly-slug transition models under reduced gravity conditions. Mishima and Ishii (1984) adopted the assumption that coalescence occurs when the gap between two bubbles is less than a bubble diameter $D_{\mathrm{b}}$, which leads to the sphere of influence being $1.5 D_{\mathrm{b}}$. Hence the critical void fraction at the transition is given by

$$
\alpha=\frac{D_{\mathrm{b}}^{3}}{\left(1.5 D_{\mathrm{b}}\right)^{3}}=0.296 \approx 0.3 .
$$

This assumption still holds under reduced gravity conditions. In addition, by taking account of the frictional pressure drop, the void-fraction-weighted drift velocity is modified as (Hibiki et al. 2006)

$$
V_{\mathrm{gj}}=\sqrt{2}\left[\frac{\left(\Delta \rho g+M_{\mathrm{F} \infty}\right) \sigma}{\rho_{\mathrm{f}}^{2}}\right]^{1 / 4} \frac{18.67(1-\alpha)^{2}\left[\frac{\Delta \rho g(1-\alpha)+M_{\mathrm{F}}}{\Delta \rho g+M_{\mathrm{F} \infty}}\right]}{1+17.67(1-\alpha)^{6 / 7}\left[\frac{\Delta \rho g(1-\alpha)+M_{\mathrm{F}}}{\Delta \rho g+M_{\mathrm{F} \infty}}\right]^{3 / 7}} .
$$

Note that this criterion is not applicable in some situations where bubbles cannot freely pack with each other, such as flows in extremely small diameter pipe.

\subsubsection{Slug to annular (churn) flow transition}

Mishima and Ishii (1984) attempted to find the mean void fraction in the slug bubble section and equate it to the mean void fraction over the entire region. At first, potential flow analysis was adopted to estimate the mean void fraction of the slug bubble section. However, the wall friction effect on the liquid flow was not considered. By considering body acceleration due to friction pressure drop, the Bernoulli equation of the flow field around the slug bubble in Fig. $2 \mathrm{~b}$ becomes

$$
\frac{\rho_{f}}{2}\left[\left(\alpha v_{\mathrm{r}}\right)^{2}-0^{2}\right]=\Delta \rho g_{\mathrm{B}} h,
$$

where $v_{\mathrm{r}}$ is bubble relative velocity, and $h$ is distance from the nose of a slug bubble. The resultant local void fraction at a distance from the nose becomes

$$
\alpha(h)=\frac{\sqrt{2 g_{\mathrm{B}} h \Delta \rho / \rho_{\mathrm{f}}}}{\sqrt{2 g_{\mathrm{B}} h \Delta \rho / \rho_{\mathrm{f}}}+\left(C_{0}-1\right) j+0.35 \sqrt{\Delta \rho g_{\mathrm{B}} D / \rho_{\mathrm{f}}}},
$$


where $D$ is the hydraulic diameter of a pipe.

Secondly, to find the length of a slug bubble, Mishima and Ishii applied force balance to the liquid film around the slug bubble. The force consisted of gravity force and wall friction:

$$
\frac{f}{2} \rho_{\mathrm{f}} v_{\mathrm{fsb}}^{2} \pi D=\frac{2}{3} \Delta \rho g_{\mathrm{G}} A\left(1-\alpha_{\mathrm{sb}}\right),
$$

where $v_{\mathrm{fsb}}$ is the terminal film velocity in the slug bubble section, and $\alpha_{\mathrm{sb}}$ is the void fraction corresponding to the terminal film velocity. This equation is not modified here because it already took account of the effect of gravity on the wall shear. Furthermore, Eq. (20) also suggests that the terminal film velocity becomes zero under zero gravity condition. This assumption is reasonable, because there is actually no force pushing the liquid film flow downwards.

The final transition criterion is modified as

$$
\alpha_{\mathrm{m}} \geq 1-0.813\left[\frac{\left(C_{0}-1\right) j+0.35 \sqrt{\Delta \rho g_{\mathrm{B}} D / \rho_{\mathrm{f}}}}{j+0.75\left\{\frac{\Delta \rho g_{\mathrm{G}} D}{\rho_{\mathrm{f}}}\right\}^{1 / 2}\left\{\frac{\Delta \rho g_{\mathrm{G}} D^{3}}{\rho_{\mathrm{f}} v_{\mathrm{f}}^{2}}\right\}^{1 / 18}}\right]^{0.75} .
$$

Under normal or reduced gravity conditions, where churn flow occurs, Eq. (21) can be used to predict the transition between slug and churn flow. Nonetheless under microgravity, as explained earlier, churn flow regime is replaced by other regimes such as frothy slug-annular (Zhao and Rezkallah, 1993) or transitional flow (Zhao et al., 2001a; Valota et al., 2007), and hence can be grouped with annular flow. So the transition criterion in Eq. (21) can be deemed as the transition between slug and annular (churn) flow.

\subsubsection{Annular flow transition due to flow reversal}

Although down-flow of liquid film along large bubbles would not happen at zero-gravity conditions, it can still occur under reduced-gravity situations. At these environments, i.e., Moon or Mars, churn flow regime could exist, and the transition between churn and 
annular due to flow reversal in the liquid film could happen. Mishima and Ishii (1984) gave the criterion as

$$
j_{\mathrm{g}}=\sqrt{\frac{\Delta \rho g_{\mathrm{G}} D}{\rho_{\mathrm{g}}}}(\alpha-0.11) .
$$

In extending this transition to reduced gravity conditions, the gravity term, $g_{\mathrm{G}}$, in Eq. (22) is not replaced by $g_{\mathrm{B}}$ because the body acceleration due to the frictional pressure drop becomes zero at flow reversal conditions $\left(j_{\mathrm{f}}=0\right)$.

Combining Eq. (22) with drift flux model, the final transition curve can be obtained in the final form

$$
j_{\mathrm{g}}=0.11 /\left[\frac{1}{C_{0} j+V_{\mathrm{gj}}}-\sqrt{\frac{\rho_{\mathrm{g}}}{\Delta \rho g_{\mathrm{G}} D}}\right],
$$

where the void-fraction weighted area-average drift velocity is calculated with Eq. (12), which will be different from the original M-I model.

\subsubsection{Annular-mist flow transition due to onset of droplet entrainment}

As explained earlier, no flow reversal happens under zero- or micro-gravity conditions. Thus, the criterion for the churn to annular transition discussed in Section 3.3.3 would not hold. On the other hand, another criterion due to the destruction of liquid slugs or large waves by entrainment or deformation proposed by Mishima and Ishii (1984) remains sound. As is shown in Fig. 2c, entrainment happens when the drag force on the liquid wave crest from the gas-shearing flow exceeds the surface tension force

$$
F_{\mathrm{d}} \geq F_{\sigma} .
$$

After introducing non-dimensional parameters, Ishii and Grolmes (1975) obtained the transition criterion as

$$
j_{\mathrm{g}} \geq\left(\frac{\sigma g_{\mathrm{G}} \Delta \rho}{\rho_{\mathrm{g}}^{2}}\right)^{1 / 4} N_{\mu \mathrm{f}}^{-0.2},
$$

where 


$$
N_{\mu \mathrm{f}} \equiv \mu_{\mathrm{f}} /\left[\rho_{\mathrm{f}} \sigma \sqrt{\frac{\sigma}{g_{\mathrm{G}} \Delta \rho}}\right]^{1 / 2}
$$

and $\mu_{\mathrm{f}}$ is the dynamic viscosity of the liquid. To examine the applicability of this transition criterion to reduced gravity conditions, the gravity term, $g_{\mathrm{G}}$ in Eqs. (25) and (26), is set as $0.02-g_{\mathrm{N}}\left(0.196 \mathrm{~m} / \mathrm{s}^{2}\right)$, and the obtained superficial gas velocity, $j_{\mathrm{g}}$, is 0.457 times the original $j_{\mathrm{g}}$ value by using $g_{\mathrm{G}}=9.81 \mathrm{~m} / \mathrm{s}^{2}$. Although the use of a value of $g_{\mathrm{G}}$ chosen to fit the data cannot be justified at a fundamental level, it is interesting to note that, choosing $g_{\mathrm{G}}=0.02 g_{\mathrm{N}}$ (which, incidentally, is the typical value prevailing in the parabolic flights were most of the data were obtained) does result in an acceptable correlation. It should be noted here that the application of Eq. (25) may result in unphysical result because $j_{\mathrm{g}}=0 \mathrm{~m} / \mathrm{s}$ at $g_{\mathrm{G}}=0 \mathrm{~m} / \mathrm{s}^{2}$. There is very limited date taken at purely zero gravity level and thus the flow regime transition criterion very close to zero gravity should be readdressed when the mechanism and data become available in future studies.

\section{Results and discussion}

Figures 3-10 show all the datasets in Table 1 according to working fluids and investigators. Figure 3 depicts the adiabatic air-carbogal data (Zhao et al., 2001a). Figure 4 plots the adiabatic air $/ N_{2}$-water data for channel size $6.0-25.4 \mathrm{~mm}$ (Lee et al., 1987; Dukler et al., 1988; Choi et al., 2003; Fujii et al., 1995; Heppner et al., 1975). Figures 5 and 6 contain the water data by Colin with his colleagues (Colin and Fabre, 1995; Colin et al., 1991) and Rezkallah with his colleagues (Huckerby and Rezkallah, 1992; Zhao and Rezkallah, 1993; Rite and Rezkallah, 1997; Lowe and Rezkallah, 1999), respectively. Figure 7 shows the air-water and air-glycerin/water data by Rite (1995). Figure 8 demonstrates Bousman et al.'s (1996) data on air-water, air-water/glycerin and air-water/Zonyl FSP. Figure 9 illustrates the data on heat transfer fluids such as Freon-11, R114, and R12 (Crowley and Sam, 1991; Hill et al., 1987; Hill and Best, 1991; Valota et al., 2007). Figure 10 shows the air-water data in a capillary tube at Earth surface gravity $\left(1-g_{\mathrm{N}}\right)$ by Galbiati and Andreini (1994). 
Figures 3-10 also compare the microgravity data with the predictions by the present model (red thick curves) and other existing models at microgravity $\left(\sim 0-g_{\mathrm{N}}\right)$ conditions on the $j_{\mathrm{g}}-j_{\mathrm{f}}$ plane. As is shown by arrows in Fig. 3, the bubbly to slug transition "B-S" is shown in red thick solid curve, the slug to annular (churn) " $\mathrm{S}-\mathrm{A}(\mathrm{C})$ " transition is drawn as red thick dash curves, and both have a slope close to $45^{\circ}$. The annular-mist flow transition (due to droplet entrainment) calculated with Eq. (25) is plotted with red thick dash-dot line located at the top right on the flow regime map. According to Mishima and Ishii (1984), this transition is actually between slug and annular (mist) flows, "S-A(M)", rather than between churn and annular flow. In summary, these three curves can predict the transitions between bubbly, slug, and annular flows.

The other existing models are also shown in the figures. Eqs. (1)-(3) are located with thin purple short-dash, magenta dot, and cyan short-dash-dot lines, respectively, with a $45^{\circ}$ inclination. The predictions by Eqs. (4) and (5) are shown by two vertical lines (grey solid line: S-FSA transition, black dash line: FSA-A transition). In addition, the B-S transition prediction by Eq. (6) is a blue dash-dot line parallel to Eqs. (1)-(3). Finally, the S-A transition (green dash-dot-dot line) predicted by Eq. (7), depending on the value of $S u$, is either an inclined line in Fig. 3a-d or a vertical line in Fig. 3e-f. The legends of the transition curves in Figs. 4-10 are the same as those in Fig. 3. Note that the B-S transition curves predicted by the present model and Eqs. (1), (2) (3) and (6) are not shown in Figure 10 because they are not suitable for capillary tubes due to the reason explained in Section 3.3.1, and only data of slug and annular regimes are plotted.

\subsection{Comparison of the present model with existing models and datasets}

\subsubsection{Bubbly to slug flow transition}

A total of six models of the bubbly-slug transition are plotted on $j_{\mathrm{f}}$ vs. $j_{\mathrm{g}}$ map. Eqs. (1)(3) do not depend on any other parameters and are $45^{\circ}$-angle lines, with Eq. (3) on the left, Eq. (2) in the middle, and Eq. (1) on the right. In addition, the B-S transition curve predicted by Eq. (6) is also parallel to these three equations, since it can be rewritten as 


$$
j_{\mathrm{f}}=\frac{1}{464.16}\left(\frac{v_{\mathrm{f}}}{v_{\mathrm{g}}}\right) S u^{2 / 3} j_{\mathrm{g}},
$$

which is also subject to fluid properties and pipe diameter. Similarly, the predicted curve of the present model at $0-g_{\mathrm{N}}$ is almost parallel to them, but it deviates from $45^{\circ}$ to the right when superficial gas velocity decreases. From the drift flux model, the superficial liquid velocity can be found as

$$
j_{\mathrm{f}}=\left(\frac{1}{C_{0}\langle\alpha\rangle}-1\right) j_{\mathrm{g}}-V_{\mathrm{gj}} .
$$

If the first term on the right hand side of Eq. (28) is dominant, $j_{\mathrm{f}}$ will be proportional to $j_{\mathrm{g}}$, and the curve on the $j_{\mathrm{g}}-j_{\mathrm{f}}$ plane will have a slope of $45^{\circ}$. However, because of the existence of the frictional pressure gradient, the drift velocity would not be equal to zero at $0-g_{\mathrm{N}}$ conditions. Thus the predicted curve of the present model on the $j_{\mathrm{g}}-j_{\mathrm{f}}$ plane will deviate to the right when superficial gas velocity decreases.

Figures 3-9 show that the present model agrees generally well with the experimental data at the B-S transition. Nevertheless, among other existing models, the line of Eq. (1) is closest to the present model and fits the data rather better than other models. The line of Eq. (6) has poor agreement with the Freon data in Fig. 9.

\subsubsection{Slug to annular (churn) flow transition}

As is shown in Figs. 3-10, the prediction by Eq. (4) (Zhao and Rezkallah, 1993) of S-toFSA transition is a vertical solid line on the $j_{\mathrm{g}}-j_{\mathrm{f}}$ plane because the transition is assumed to depend on a Weber number, which is only subject to superficial gas velocity. The prediction by Eq. (7) (Jayawardena et al., 1997) on a broader S-A transition is a vertical or a $45^{\circ}$ dash-dot-dot line depending on $S u$ value. Similarly, the prediction of the present model at $0-g_{\mathrm{N}}$ for the $\mathrm{S}-\mathrm{C}$ transition is approximately parallel to that for the $\mathrm{B}-\mathrm{S}$ transition, due to the same reason explained in the last section. However, the slope difference between the present model and Eq. (7) is more significant for capillary tube data at $1-g_{\mathrm{N}}$.

In Figs. 3-10, only two data points of churn flow are plotted, as in Fig. 4 (c). As explained in Section 2.1, the slug to churn transition is actually the transition between 
slug to annular (churn) flow. The agreement between the present model and the various datasets is fairly good. In addition, Jayawardena et al.'s (1997) correlation was developed using the air-water and Freon datasets, and generally agrees with the majority of the data, except air-carbogal data and $1-g_{\mathrm{N}}$ capillary tube data. Moreover, Zhao and Rezkallah's model of the S-FSA transition in Eq. (4) agrees well with their own data in Figs. 6 and 7, but tends to underestimate compared with other datasets.

\subsubsection{Slug to annular-mist flow transition}

The prediction by the present model on the S-A transition at $1-g_{\mathrm{N}}$ does not depend on $j_{\mathrm{f}}$, as shown in Eq. (25). Rather it is represented by a vertical line. Since the contribution of gravity to the actual body acceleration is negligible for the $\mathrm{S}-\mathrm{A}(\mathrm{M})$ transition, the original M-I model is not changed, and the value of $0.02 g_{\mathrm{G}}$ is chosen for $g_{\mathrm{G}}$ for microgravity conditions because majority of the experiments in literature were performed at parabolic flight. Existing model being compared is Eq. (5) (Zhao and Rezkallah, 1993) on the FSA-A transition at $0-g_{\mathrm{N}}$, which is mostly located on the right of the present model, except for large pipe diameter $(D \geq 19 \mathrm{~mm})$ in air-water condition and data of R114 and R12 in Fig. 9. Nevertheless, when $S u>10^{6}$, Jayawardena et al.'s (1997) prediction on slug to annular transition also gives a vertical line, which is on the left of the line of Eq. (5), except for Fig. 3 (d) which has a pipe size of $40 \mathrm{~mm}$. For cases where $S u<10^{6}$, the $45^{\circ}$ line predicted by Jayawardena et al. (1997) is hard to compare with the present $\mathrm{S}-\mathrm{A}(\mathrm{M})$ models.

Figures 3-10 show that the present model generally agrees well with the majority of existing datasets. Annular-mist flow and roll wave in microgravity have been observed by several researchers (Bousman, et al. 1996; Zhao and Rezkallah, 1993; Dukler et al. 1988). There is a plenty of evidence of the occurrence of entrainment in microgravity. Zhao and Rezkallah's model in Eq. (5) of the FSA-A transition fits well with their own data in Figs. 4 and 5-(a), but over-predicts against other databases.

\subsection{Sample computation of the present model at reduced gravity conditions}

To examine the effect of gravity on two-phase flow regime transition, sample computations of the present model (thick lines) and the original M-I model (thin lines) 
were performed at various gravity levels. Major assumptions for these calculations were (1) air-water at 1 atmosphere and (2) a pipe size of $25.4 \mathrm{~mm}$. Figure 11 plots the flow regime transition on the $j_{\mathrm{g}}-j_{\mathrm{f}}$ plane under $0.02-g_{\mathrm{N}}\left(0.196 \mathrm{~m} / \mathrm{s}^{2}\right), 0.165-g_{\mathrm{N}}\left(1.62 \mathrm{~m} / \mathrm{s}^{2}\right)$, $0.379-g_{\mathrm{N}}\left(3.71 \mathrm{~m} / \mathrm{s}^{2}\right)$, and $1-g_{\mathrm{N}}\left(9.81 \mathrm{~m} / \mathrm{s}^{2}\right)$, corresponding to micro-, lunar, Martian and Earth surface gravity respectively. Similar to Fig. 3, the B-S transition curves are on the left, the $\mathrm{S}-\mathrm{A}(\mathrm{C})$ transition curves are in the middle, $\mathrm{C}-\mathrm{A}$ (churn-to-annular transition due to flow reversal) are located the right bottom, and the $\mathrm{S}-\mathrm{A}(\mathrm{M})$ transition boundaries are plotted on the right and top.

The prediction of the original $\mathrm{M}-\mathrm{I}$ model for $\mathrm{B}-\mathrm{S}$ transition at $0-g_{\mathrm{N}}$ is $45^{\circ}$-angle line, because the void-fraction-weighted drift velocity becomes zero at zero gravity, and the transition line becomes

$$
j_{\mathrm{f}}=\left(\frac{1}{C_{0}\langle\alpha\rangle}-1\right) j_{\mathrm{g}} \text {. }
$$

However, at $1-g_{\mathrm{N}}$, due to the existence of $V_{\mathrm{gj}}$, the prediction of the M-I model shifts right as $j_{\mathrm{f}}$ decreases. Another interesting observation of the figures is that the predictions by the M-I model at $1-g_{\mathrm{N}}$ and $0-g_{\mathrm{N}}$ are close to each other at a higher mixture volumetric flux. This suggests that the effect of gravity becomes insignificant as the mixture volumetric flux increases.

In the present model, because of the frictional pressure gradient, the drift velocity would not be equal to zero at $0-g_{\mathrm{N}}$ conditions. Thus the predicted curve of the present model on the $j_{\mathrm{g}}-j_{\mathrm{f}}$ plane is on the right of the M-I model. Nevertheless, the difference caused by frictional pressure drop is less under $1-g_{\mathrm{N}}$ conditions. For the majority of working fluids, $V_{\mathrm{gj}}$ in the present model deviates from that in the M-I model after $j_{\mathrm{g}}$ reaches $1 \mathrm{~m} / \mathrm{s}$, and becomes about doubled in value when $j_{\mathrm{g}}$ is $10 \mathrm{~m} / \mathrm{s}$. The exceptionally high drift velocities are for high-pressure air-water flow in a capillary tube $(D=1 \mathrm{~mm})$, where $V_{\mathrm{gj}}$ will increase up to 8 times the original value. For these three conditions, the deviation of the resultant bubbly to slug transition curves from $45^{\circ}$-angle is much wider, which can be seen in Fig. 10.

For similar reason, the prediction of the original $\mathrm{M}-\mathrm{I}$ model at $0-g_{\mathrm{N}}$ on $\mathrm{S}-\mathrm{A}(\mathrm{C})$ transition is a $45^{\circ}$-inclination straight line. But the $\mathrm{S}-\mathrm{A}(\mathrm{C})$ transition by the present 
model is located higher than that by the original M-I model, because present model predicts lower void fraction than the M-I model, as suggested in Eq. (21). With an increase in gravity from $0-g_{\mathrm{N}}$ to $1-g_{\mathrm{N}}$, both void fraction and drift velocity increase, which pushes the transition further away from the original $45^{\circ}$ angle, and the $\mathrm{S}-\mathrm{A}(\mathrm{C})$ transition lines moves right as superficial gas velocity decreases. For both B-S and $\mathrm{S}-\mathrm{A}(\mathrm{C})$ transitions, the differences between the present model and the $\mathrm{M}-\mathrm{I}$ model under lunar, Martian and Earth surface gravity are very small. In addition, as mixture velocity increases, the difference in gravity level decreases on the $j_{\mathrm{g}}-j_{\mathrm{f}}$ plane. This is because the effect of gravity is reduced as the two-phase mixture volumetric flux moves faster.

For annular flow transitions due to flow reversal and onset of droplet entrainment, different gravity level causes different superficial gas velocity, with higher $j_{\mathrm{g}}$ for higher $g_{\mathrm{G}}$ value. The predicted annular flow transition curves due to flow reversal are close to a vertical line on the $j_{\mathrm{g}}-j_{\mathrm{f}}$ plane, which means that superficial liquid velocity has weak effect on the transition. Their $j_{\mathrm{g}}$ values are smaller than those for annular flow transition due to onset of droplet entrainment. 


\section{Conclusions}

Flow regime transition criteria are of practical importance for two-phase flow analyses at reduced gravity conditions. In view of this, flow regime transition criteria, which take the gravity effect into account, were studied in detail. The results are as follows:

(1) Literature survey found that churn flow regime does not exist under micro-gravity conditions, where only three flow regimes occur: bubbly, slug, and annular. However, under other reduced-gravity conditions, such as Moon or Mars, four main flow regimes exist: bubbly, slug, churn, and annular.

(2) The flow regime transition criteria, which takes the frictional pressure loss effect into account, was developed by extending Mishima and Ishii's model (1984) to reduced gravity conditions. The bubbly-to-slug flow transition adopted the modified drift velocity considering the frictional pressure loss effect; the slug-toannular (churn) flow transition criterion was re-derived by considering reduced gravity effect; the annular flow transition criterion due to flow reversal was removed for zero-gravity conditions; and the annular-mist flow transition criterion due to onset of droplet entrainment in the original $\mathrm{M}-\mathrm{I}$ model was adopted by considering that the gravitational acceleration was kept as a $0.02-g_{\mathrm{N}}$ $\left(0.196 \mathrm{~m} / \mathrm{s}^{2}\right)$ for micro-gravity conditions.

(3) A comparison of the newly developed flow regime transition criteria model with various experimental datasets taken at microgravity conditions shows satisfactory agreement.

(4) Sample computations of the newly developed flow regime transition criteria model were performed at various gravity conditions, for example 0.196, 1.62, 3.71 , and $9.81 \mathrm{~m} / \mathrm{s}^{2}$, corresponding to micro-gravity and lunar, Martian and Earth surface gravity, respectively. It can be revealed that for bubbly-slug transition and slug-annular (churn) transition, the effect of gravity on flow regime transition in a two-phase flow system is more pronounced at the low liquid flow condition, whereas the gravity effect can be ignored at high mixture volumetric flux conditions. However, for the annular flow transition due to flow reversal and 
onset of droplet entrainment, higher superficial gas velocity is obtained at higher gravity level.

\section{Acknowledgements}

Part of this work was supported by 2008 Queensland University of Technology Early Career Researcher Grants (funded by the Faculty of Built Environment and Engineering). The authors wish to thank Professor Ted Steinberg for his support. 


\section{References}

Bousman, W.S., McQuillen, J.B., Witte, L.C., 1996. Gas-liquid flow patterns in microgravity: effects of tube diameter, liquid viscosity and surface tension. Int. J. Multiphase Flow 22, 1035-1053.

Brauner, N., 1990. On the relations between two-phase flows under reduced gravity and Earth experiment. Int. Comm. Heat Mass Transfer 17, 271-282.

Choi, B., Fujii, T., Asano, H., Sugimoto, K., 2003. A study of the flow characteristics in air-water two-phase flow under microgravity (results of flight experiments). JSME Int. J. Series B 46, 262-269.

Colin, C., Fabre, J., 1995. Gas-liquid pipe flow under microgravity conditions: influence of tube diameter on flow patterns and pressure drops. Adv. Space Res. 16, 133137.

Colin, C., Fabre, J., Dukler, A.E., 1991. Gas-liquid flow at microgravity conditions - I dispersed bubble and slug flow. Int. J. Multiphase Flow 17, 533-544.

Crowley, C.J., Sam, R.G., 1991. Microgravity experiments with a simple two-phase thermal system. Report No. PL-TR-91-1059, Phillips Lab. Kirtland Air Force Base, NM, USA.

Dukler, A.E., Fabre, J.A., McQuillen, J.B., Vernon, R., 1988. Gas-liquid flow at microgravity conditions: flow patterns and their transitions. Int. J. Multiphase Flow 14, 389-400.

Fujii, T., Asano, H., Nakazawa, T., Yamada, H., 1995. Flow characteristics of gas-liquid two-phase flow under microgravity condition. In: Proc. $2^{\text {nd }}$ Int. Conf. Multiphase Flow '95- Kyoto, Japan Society of Multiphase Flow, Japan, pp. P6-1 - P6-5.

Galbiati, L., Andreini, P., 1994. Flow pattern transition for horizontal air-water flow in capillary tubes. A microgravity "Equivalent system" simulation. Int. Comm. Heat Mass Transfer 21, 461-468.

Grigoriev, Y.I., Grogorov, E.I., Cykhotsky, V.M., Prokhorov, Y.M., Gorbenco, G.A., Blinkov, V.N., Teniakov, I.E., Malukihin, C.A., 1996. Two-phase heat transport loop of central thermal control system for the international space station "Alpha" Russian segment. In: AIChE Symposium Series--Heat Transfer. 310, 9-17.

Heppner, D.B., King, C.D., Littles, J.W., 1975. Zero-gravity experiments in two-phase 
fluids flow pattern. ICES Conference, San Francisco, CA, ASME Paper No. TSENAs-24.

Hibiki, T., Hazuku, T., Takamasa, T., Ishii, M., Interfacial-area transport equation at reduced-gravity conditions, AIAA Journal 47, 1123-1131.

Hibiki, T., Ishii, M., 2003. One-dimensional drift-flux model and constitutive equations for relative motion between phases in various two-phase flow regimes. Int. J. Heat Mass Transfer 46, 4935-4948.

Hibiki, T., Takamasa, T., Ishii, M., 2004. One-dimensional drift-flux model and constitutive equations for relative motion between phases in various two-phase flow regimes at microgravity conditions. Proc. $12^{\text {th }}$ Int. Conf. Nucl. Eng., Arlington, USA, Paper No.: ICONE12-49037, 2004.

Hibiki, T., Takamasa, T., Ishii, M., Gabriel, K.S., 2006. One-dimensional drift-flux model at reduced gravity conditions. AIAA J. 44, 1635-1642.

Hill, W.S., Best, F.R., 1991. Microgravity two-phase flow experiment and test results. $21^{\text {st }}$ Int. Conf. Environmental Systems, San Francisco, CA, SAE Paper No 911556.

Hill, D., Downing, S., Rogers, D., Teske, D., Niggemann, R., 1987. A study of two-phase flow in a reduced gravity environment. Final report DRL No. T-1884, Sunstrand Energy Systems, Rockford, IL, USA.

Huckerby, C.S., Rezkallah, K.S., 1992. Flow pattern observations in two-phase gas-liquid flow in a straight tube under normal and microgravity conditions. AIChE Symposium Ser. 88, 139-147.

Ishii, M., Grolmes, M.A., 1975. Inception criteria for droplet entrainment in two-phase concurrent film flow. AIChE J. 21, 308-318.

Kachnik, L., Lee, D., Best, F., Faget, N., 1987. A microgravity boiling and convective condensation experiment. ASME Winter Annual Meeting, Boston, MA, USA, ASME Paper No. 87-WA/HT-12, pp. 1-5.

Karri, S.B.R., Mathur, V.K., 1988. Two-phase flow regime map predictions under microgravity. AIChE J. 34, 137-139.

Jayawardena, S.J., Balakotaiah, V., Witte, L.C., 1997. Flow pattern transition maps for microgravity two-phase flows. AICHE Journal 43, 1637-1640.

Lee, D., Best, F.R., McGraw, N., 1987. Microgravity two-phase flow regime modeling. 
Proc. $3^{\text {rd }}$ Nucl. Therm. Hydraul., Los Angeles, CA, 94-100.

Lockhart, R.W., Martinelli, R.C., 1949. Proposed correlation of data for isothermal twophase, two-component flow in pipes. Chem. Eng. Prog. 5, 39-48.

Lowe, D.C., Rezkallah, K.S., 1999. Flow regime identification in microgravity two-phase flows using void fraction signals. Int. J. Multiphase Flow 25, 433-457.

Mishima, K., Ishii, M., 1984. Flow regime transition criteria for upward two-phase flow in vertical tubes. Int. J. Heat Mass Transfer 27, 723-737.

Rezkallah, K.S., Zhao, L., 1995. A flow pattern map for two-phase liquid-gas flows under reduced gravity conditions. Adv. Space Res. 16, 133-137.

Rezkallah, K.S., 1996. Weber number based flow-pattern maps for liquid-gas flows at microgravity. Int. J. Multiphase Flow 22, 1265-1270.

Rite, R.W. Heat transfer in gas-liquid flows through a vertical, circular tube under microgravity conditions. Ph.D. thesis, University of Saskatchewan, Canada, 1995.

Rite, R.W., Rezkallah, K.S., 1997. Local and mean heat transfer coefficients in bubbly and slug flows under microgravity conditions. Int. J. Multiphase Flow 23, 37-54.

Takamasa, T., Hazuku, T., Fukamachi, N., Tamura, N. Hibiki, T., Ishii, M., 2004. Effect of gravity on axial development of bubbly flow at low liquid Reynolds number. Exp. Fluids 37, 631-644; also Erratum, 38 (2005) pp. 700.

Takamasa, T., Iguchi,T. Hazuku, T. Hibiki, T., Ishii, M., 2003. Interfacial area transport of bubbly flow under microgravity environment. Int. J. Multiphase Flow 29, 291304.

Tomiyama, A., Kataoka, I., Zun, I., Sakaguchi, T., 1998. Drag coefficients of single bubbles under normal and micro gravity conditions. JSME Int. J. Ser. B 41, 472479.

Vasavada, S., Sun, X., Ishii, M., Duval, W., 2007. Study of two-phase flows in reduced gravity using ground based experiments. Exp. Fluids 43, 53-75.

Valota, L., Kurwitz, C., Shephard, A., Best, F., 2007. Microgravity flow regime data and analysis. Int. J. Multiphase Flow 33, 1172-1185.

Zhao, J.F., Xie, J.C., Lin, H., Hu, W.R., 2001a. Microgravity experiments of two-phase flow patterns aboard MIR space station. ACTA Mechanica Sinica 17, 151-159.

Zhao, J.F., Xie, J.C., Lin, H., Hu, W.R., 2001b. Experimental study on two-phase gas- 
liquid flow patterns at normal and reduced gravity conditions. Sci. China, Ser. E 44, 553-560.

Zhao, J.F., Hu, W.R., 2000. Slug to annular flow transition of microgravity two-phase flow. Int. J. Multiphase Flow 26, 1295-1304.

Zhao, L., Rezkallah, K.S., 1993. Gas-liquid flow patterns at microgravity conditions. Int. J. Multiphase Flow 19, 751-763 


\section{Captions of Tables and Figures}

Table 1. Summary of microgravity two-phase flow regime experimental investigation.

Fig. 1. Actual body acceleration at Earth surface gravity.

Fig. 2. Schematic diagram of flow regime transition.

Fig. 3. Comparison of flow regime transition models with air-carbogal data at microgravity condition.

Fig. 4. Comparison of flow regime transition models with air-water data at microgravity condition.

Fig. 5. Comparison of flow regime transition models with air-water data at microgravity condition by Colin and his colleagues.

Fig. 6. Comparison of flow regime transition models with air-water data at microgravity condition by Rezkallah and his colleagues.

Fig. 7. Comparison of flow regime transition models with air-water data at microgravity condition by Rite (1995).

Fig. 8. Comparison of flow regime transition models with data at microgravity condition by Bousman et al. (1996).

Fig. 9. Comparison of flow regime transition models with Freon data at microgravity condition.

Fig. 10. Comparison of flow regime transition models with high-pressure air-water capillary tube data at normal gravity condition.

Fig. 11. Example computation of flow regime transition map in for air-water in atmosphere at reduced gravity conditions. 
Table 1

\begin{tabular}{|c|c|c|c|c|c|c|c|c|c|c|c|c|c|c|c|c|c|}
\hline \multirow{2}{*}{ Authors } & \multirow{2}{*}{ Fluids } & \multirow{2}{*}{ Facility } & \multirow{2}{*}{$\begin{array}{c}D \\
(\mathrm{~mm})\end{array}$} & \multirow{2}{*}{$\begin{array}{c}\text { Length } \\
(\mathrm{mm})\end{array}$} & \multirow{2}{*}{$\begin{array}{c}\text { Gravity } \\
\text { level }\end{array}$} & \multicolumn{11}{|c|}{ Flow regimes } & \multirow{2}{*}{ Fig } \\
\hline & & & & & & $\mathrm{B}$ & $\mathrm{B}-\mathrm{S}$ & $\mathrm{S}$ & $\mathrm{P}$ & $\mathrm{S}-\mathrm{C}$ & $\mathrm{C}$ & $\mathrm{S}-\mathrm{T}$ & $\mathrm{T}$ & T-A & $S-A$ & $\mathrm{~A}$ & \\
\hline \multirow{3}{*}{ Bousman et al., 1996} & Air - water & \multirow{3}{*}{ KC-135 } & $\begin{array}{l}12.7 \\
25.4\end{array}$ & $\begin{array}{l}637 \\
609\end{array}$ & \multirow{3}{*}{ $\pm 0.02-g_{N}$} & $\begin{array}{l}7 \\
3\end{array}$ & $\begin{array}{l}7 \\
3\end{array}$ & $\begin{array}{l}30 \\
29\end{array}$ & & & & & & & $\begin{array}{l}18 \\
13\end{array}$ & $\begin{array}{l}33 \\
14\end{array}$ & \multirow{3}{*}{8} \\
\hline & $\begin{array}{l}\text { Air - } \\
\text { water/glycerine }\end{array}$ & & $\begin{array}{l}12.7 \\
25.4\end{array}$ & $\begin{array}{l}637 \\
609\end{array}$ & & $\begin{array}{l}4 \\
4\end{array}$ & $\begin{array}{l}4 \\
4\end{array}$ & $\begin{array}{l}20 \\
11\end{array}$ & & & & & & & $\begin{array}{l}21 \\
11\end{array}$ & $\begin{array}{l}29 \\
15\end{array}$ & \\
\hline & Air -water/Zonyl & & $\begin{array}{l}12.7 \\
25.4 \\
\end{array}$ & $\begin{array}{l}637 \\
609 \\
\end{array}$ & & $\begin{array}{l}4 \\
3 \\
\end{array}$ & $\begin{array}{l}4 \\
3 \\
\end{array}$ & $\begin{array}{l}16 \\
29 \\
\end{array}$ & & & & & & & $\begin{array}{l}7 \\
13 \\
\end{array}$ & $\begin{array}{l}28 \\
14 \\
\end{array}$ & \\
\hline Choi et al., 2002 & Air - water & MU-300 & 10 & 600 & $\pm 0.02-g_{N}$ & 20 & & 12 & 10 & & & & & & 9 & 6 & 4 \\
\hline Colin et al., 1991 & Air - water & Jet & 40 & 3170 & $<0.03-g_{\mathrm{N}}$ & 47 & & 38 & & & & & & & & & 5 \\
\hline \multirow{3}{*}{ Colin \& Fabre, 1995} & \multirow{3}{*}{ Air - water } & \multirow{3}{*}{ Jet } & 6 & \multirow{3}{*}{3170} & \multirow{3}{*}{$<0.03-g_{\mathrm{N}}$} & 17 & & 16 & & & & & & & 6 & & \multirow{3}{*}{5} \\
\hline & & & 10 & & & 17 & & 23 & & & & & & & 9 & & \\
\hline & & & 19 & & & 19 & & 26 & & & & & & & & & \\
\hline Crowley \& Sam 1991 & R11 & KC-135 & 6.35 & 952.5 & & & & 1 & & & & & & & & 8 & 9 \\
\hline \multirow{2}{*}{ Dukler et al., 1988} & \multirow{2}{*}{ Air - water } & Learjet & 12.7 & 1060 & $\leq 0.02-g_{\mathrm{N}}$ & 4 & & 9 & & & & & & & 1 & 8 & \multirow{2}{*}{4} \\
\hline & & Drop Tower & 9.525 & 457 & & 10 & & 6 & & & & & & & & & \\
\hline Fujii et al. 1995 & $\mathrm{~N}_{2}$ - water & MU-300 & 10.5 & 500 & $0.01-g_{\mathrm{N}}$ & 5 & & & 16 & & & & & & 8 & 3 & 4 \\
\hline $\begin{array}{l}\text { Galbiati \& Andreini, } \\
1994\end{array}$ & Air - water & $\begin{array}{l}\text { Capillary tubes } \\
\left(1-g_{N}\right)\end{array}$ & 1 & 250 & $1-g_{\mathrm{N}}$ & & & $\begin{array}{l}20 \\
48 \\
62 \\
\end{array}$ & & & & & & & & $\begin{array}{l}65 \\
50 \\
31 \\
\end{array}$ & 10 \\
\hline Heppner et al., 1975 & Air - water & KC-135 & 25.4 & 20 & $0.01-g_{N}$ & 5 & & & & 4 & & & & & & 24 & 4 \\
\hline Hill et al. 1987 & R114 & KC-135 & 15.8 & 1830 & $\leq 0.1-g_{\mathrm{N}}$ & & & 2 & & & & & & & 1 & 6 & 9 \\
\hline Hill \& Best, 1991 & $\mathrm{R} 12$ & KC-135 & $8.7 / 11.1$ & 2400 & $0.023-g_{\mathrm{N}}$ & & & 3 & & & & & & & & 16 & 9 \\
\hline $\begin{array}{l}\text { Huckerby \& Rezkallah, } \\
1992\end{array}$ & Air - water & KC-135 & 9.525 & 900 & & 8 & 7 & 25 & & & & & & & 9 & & 6 \\
\hline Kachnik et al. 1987 & Water (boiling) & KC-135 & $6,8,10$ & 1500 & $\pm 0.01-g_{\mathrm{N}}$ & 2 & & 2 & & & & & & & & 8 & N/A \\
\hline Karri \& Mathur 1988 & Oil - water & & 25.4 & & & 19 & 2 & 17 & & & & & & & 2 & 19 & N/A \\
\hline Lee et al. 1987 & $\begin{array}{l}\text { Air - water } \\
\mathrm{N}_{2} \text { - water }\end{array}$ & KC-135 & 6 & 750 & $\pm 0.01-g_{\mathrm{N}}$ & 2 & & 2 & & & & & & & & $\begin{array}{l}10 \\
5\end{array}$ & 4 \\
\hline Lowe \& Rezkallah 1999 & Air-water & Lewis DC-9 & 9.525 & 1050 & & 18 & 4 & 45 & & & & 5 & 30 & 7 & & 36 & 6 \\
\hline \multirow{4}{*}{ Rite, 1995} & Air-water & \multirow{4}{*}{ KC-135 } & \multirow{4}{*}{9.525} & \multirow{4}{*}{1050} & \multirow{4}{*}{$<0.03-g_{\mathrm{N}}$} & 18 & 5 & 184 & & & & & & & 83 & 44 & \multirow{4}{*}{7} \\
\hline & Air-50\%G/W & & & & & & & 16 & & & & & & & 9 & & \\
\hline & Air $-60 \% \mathrm{G} / \mathrm{W}$ & & & & & & & 20 & & & & & & & 13 & & \\
\hline & Air $-65 \% \mathrm{G} / \mathrm{W}$ & & & & & & & 23 & & & & & & & 15 & & \\
\hline
\end{tabular}




\begin{tabular}{|c|c|c|c|c|c|c|c|c|c|c|c|c|c|}
\hline Rite \& Rezkallah 1997 & Air-water & KC-135 & 9.525 & 1050 & & 12 & & 39 & 2 & & 7 & 17 & 6 \\
\hline Valota et al. 2007 & $\mathrm{R} 12$ & KC-135 & 12.7 & 1220 & & & & 19 & & 40 & & 11 & 9 \\
\hline Vasavada, et al. 2007 & $\begin{array}{l}\text { Water-Therminol } \\
59\end{array}$ & & 25.4 & 2800 & $1-g_{\mathrm{N}}$ & 15 & 3 & 2 & & & & & N/A \\
\hline Zhao \& Rezkallah 1993 & Air-water & KC-135 & 9.52512 .7 & 1050 & $<0.03-g_{\mathrm{N}}$ & 7 & & 44 & & & 51 & 16 & 6 \\
\hline Zhao et al., 2001a & Air-carbogal & MIR & 10 & 356 & $0-g_{N}$ & 13 & & 2 & & 15 & & 11 & 3 \\
\hline Zhao et al. 2001b & Air-water & IL-76 & $\begin{array}{l}\text { Square } \\
12 \times 12\end{array}$ & 960 & $<0.04-g_{\mathrm{N}}$ & 14 & & 7 & & & 14 & 5 & N/A \\
\hline
\end{tabular}

Noting: B (Bubbly), S (Slug),P (Plug), C (Churn), T (Transition), A (Annular) 
Fig. 1

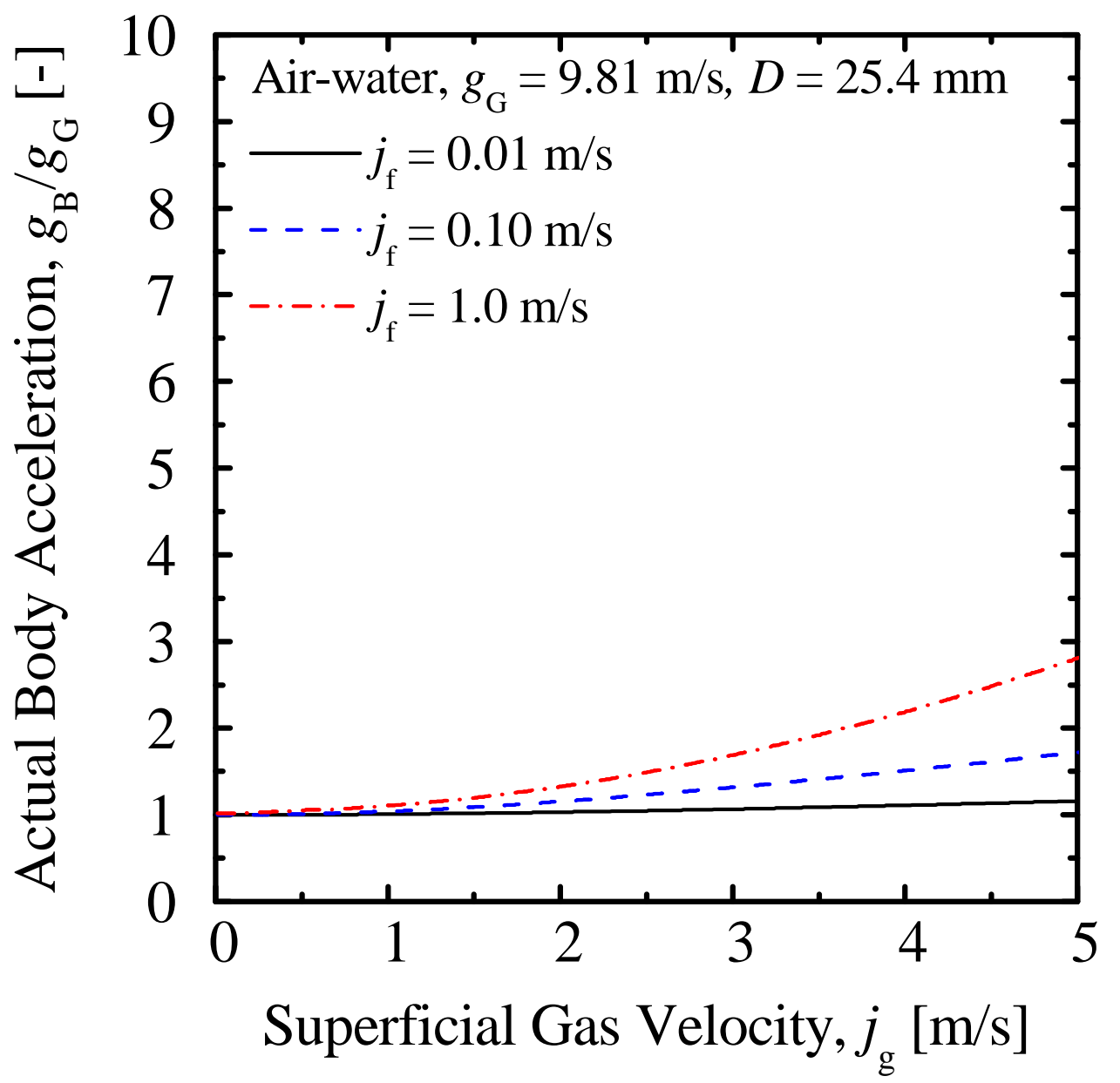


Fig. 2

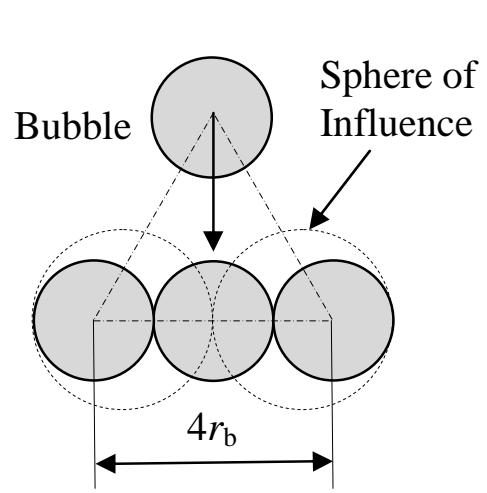

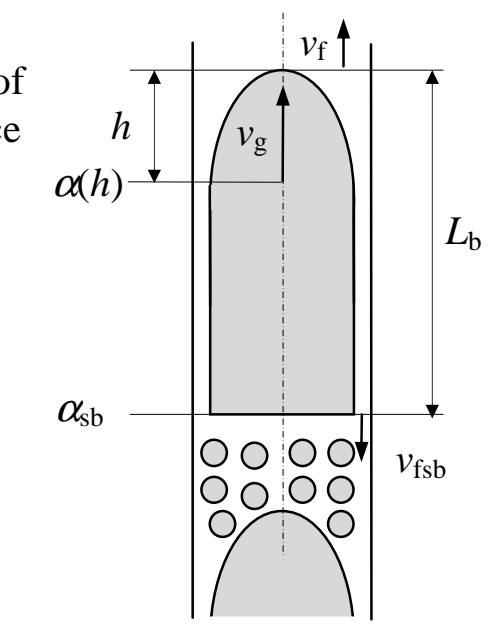

b) Slug-Churn

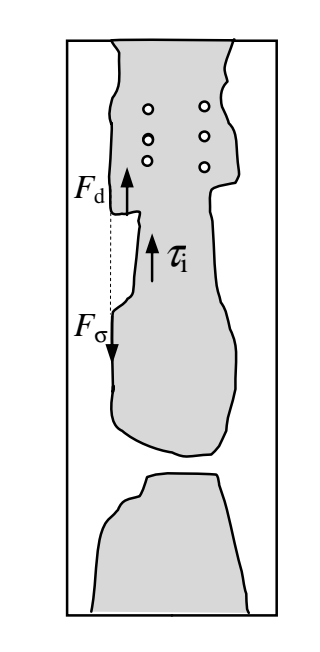

c) Churn-Annular a) Bubbly-Slug 
Fig. 3

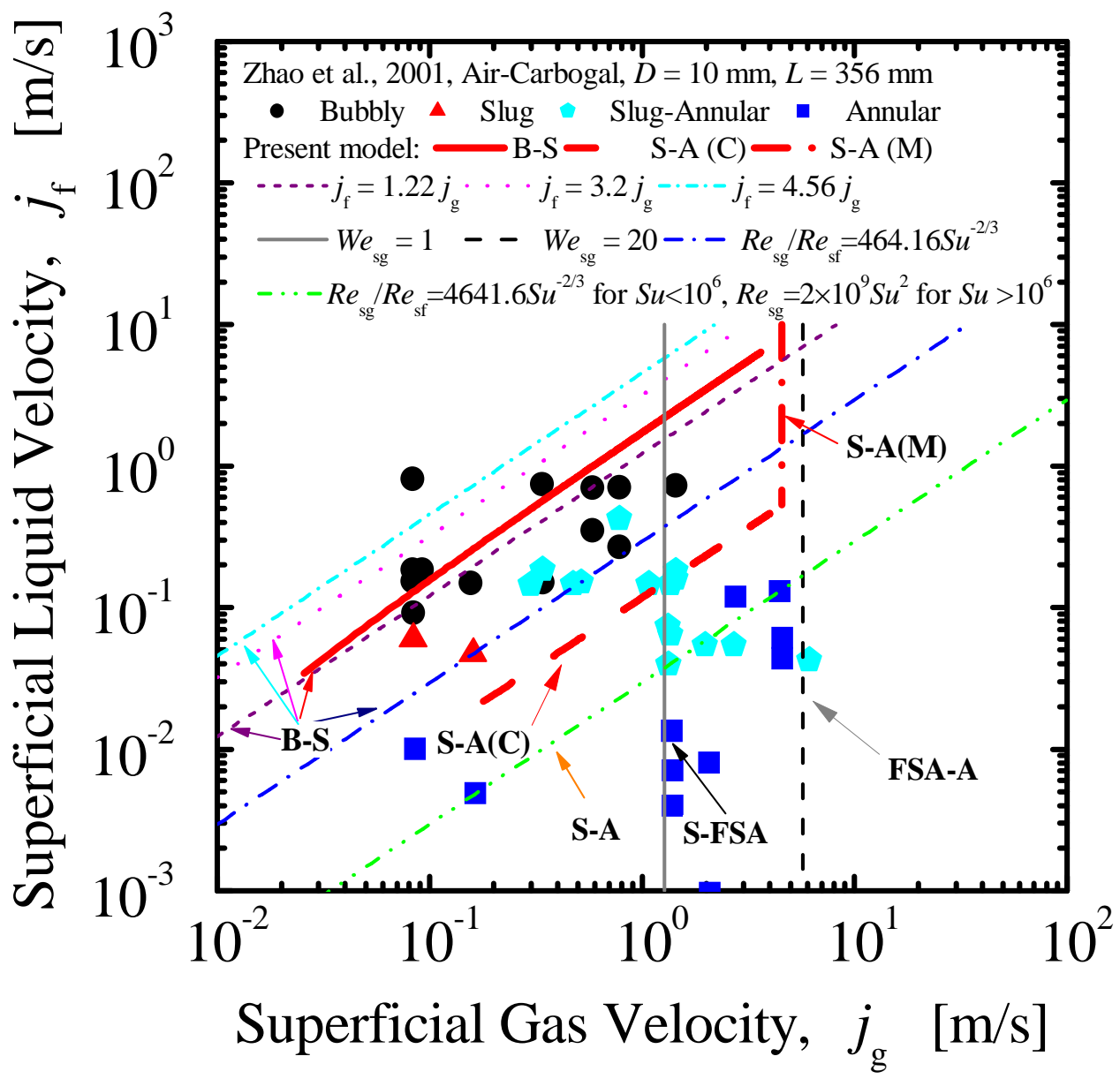


Fig. 4
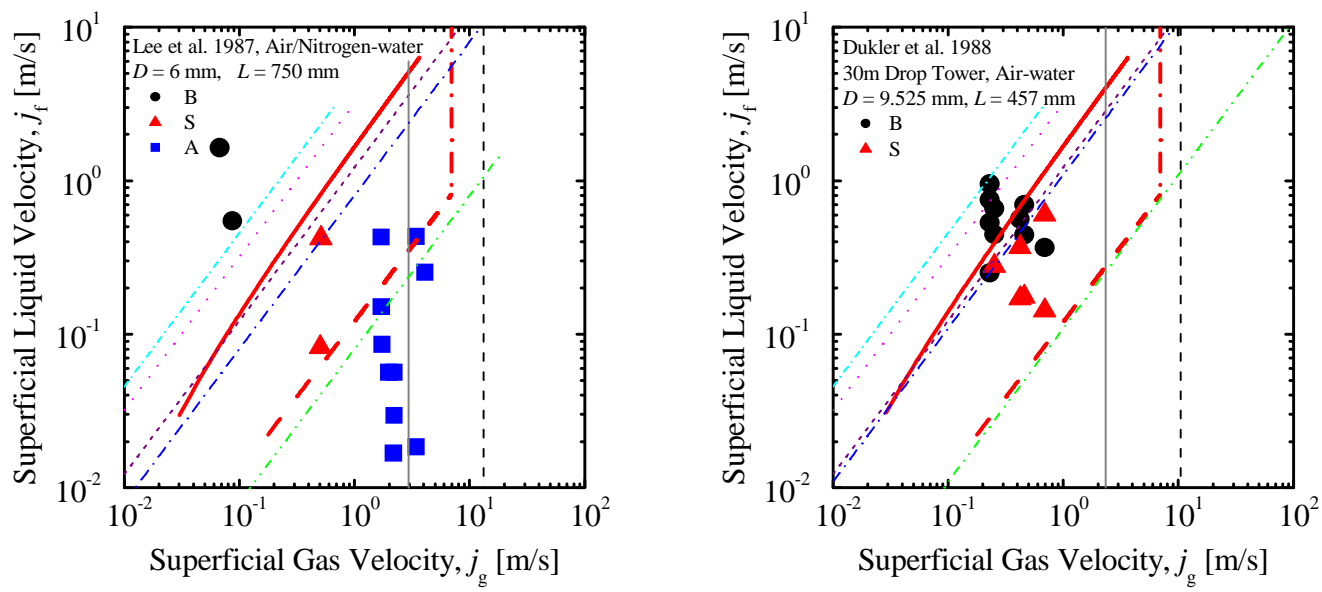

a

b
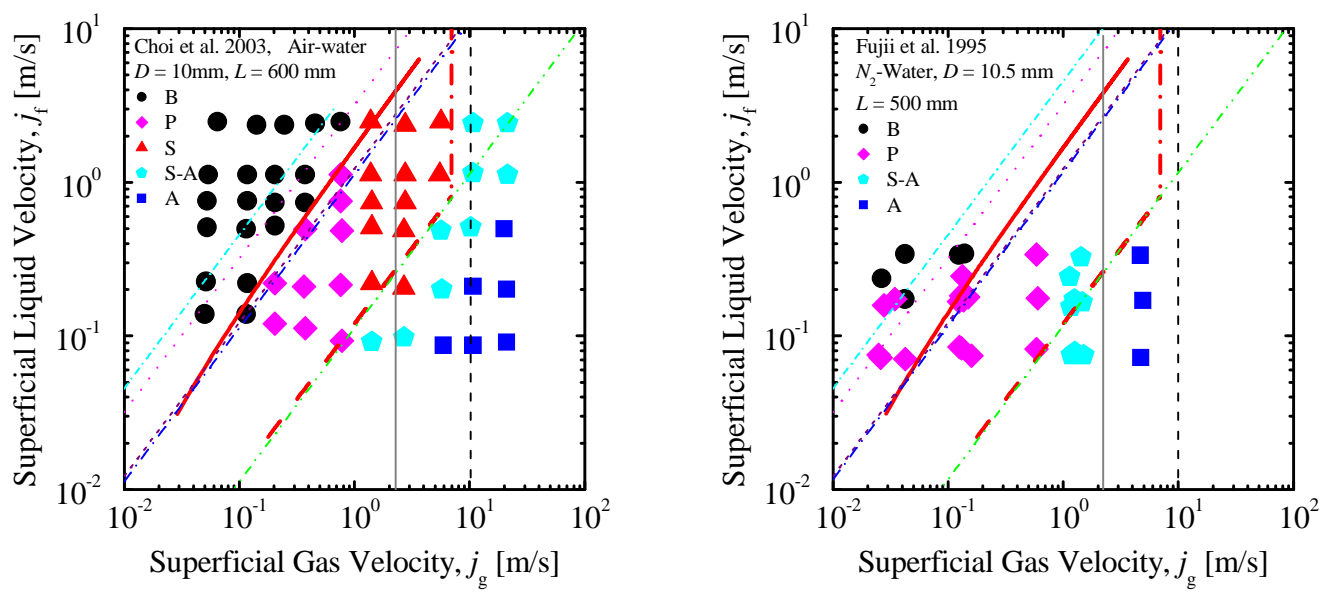

c

d
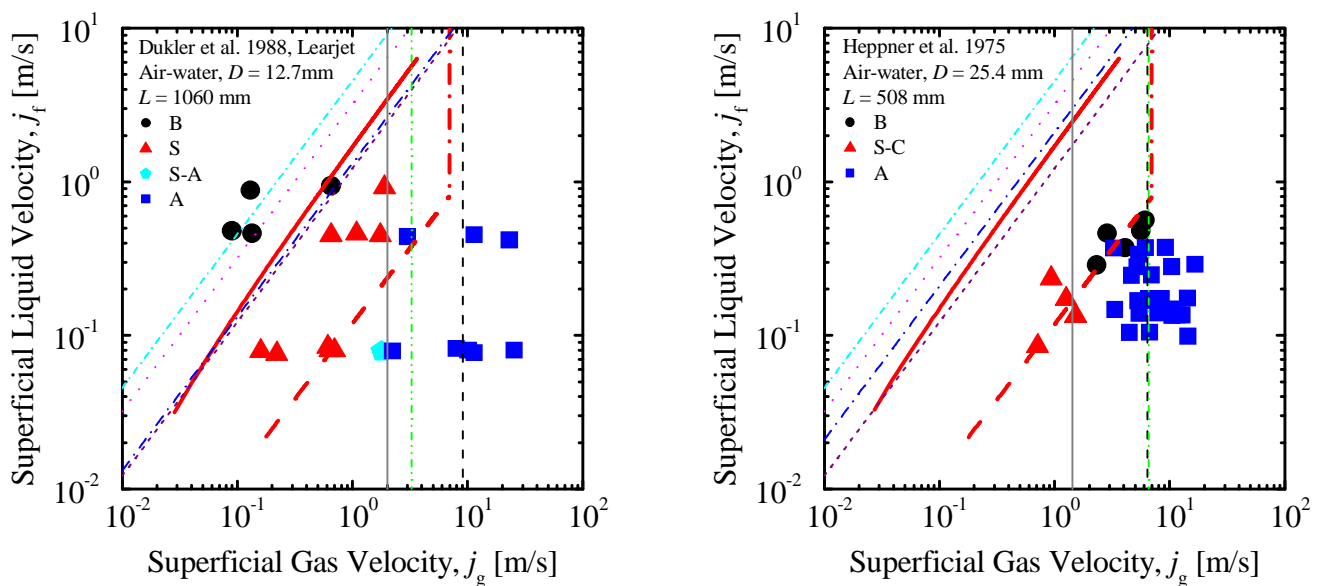

e 
Fig. 5
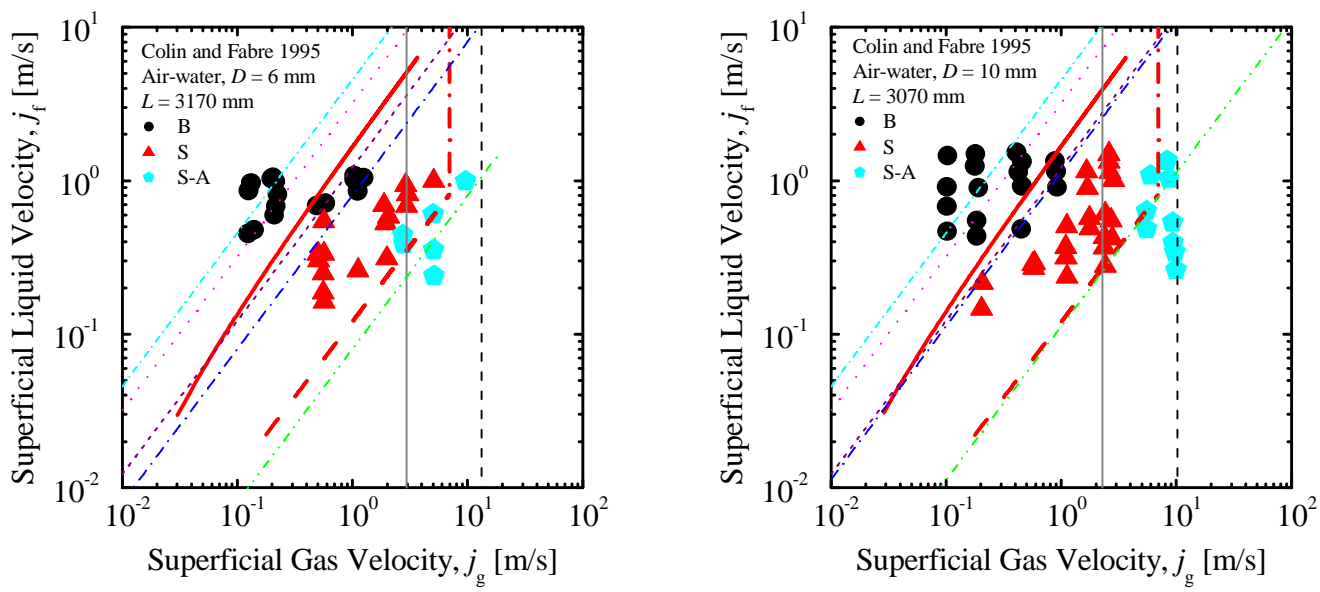

a

b
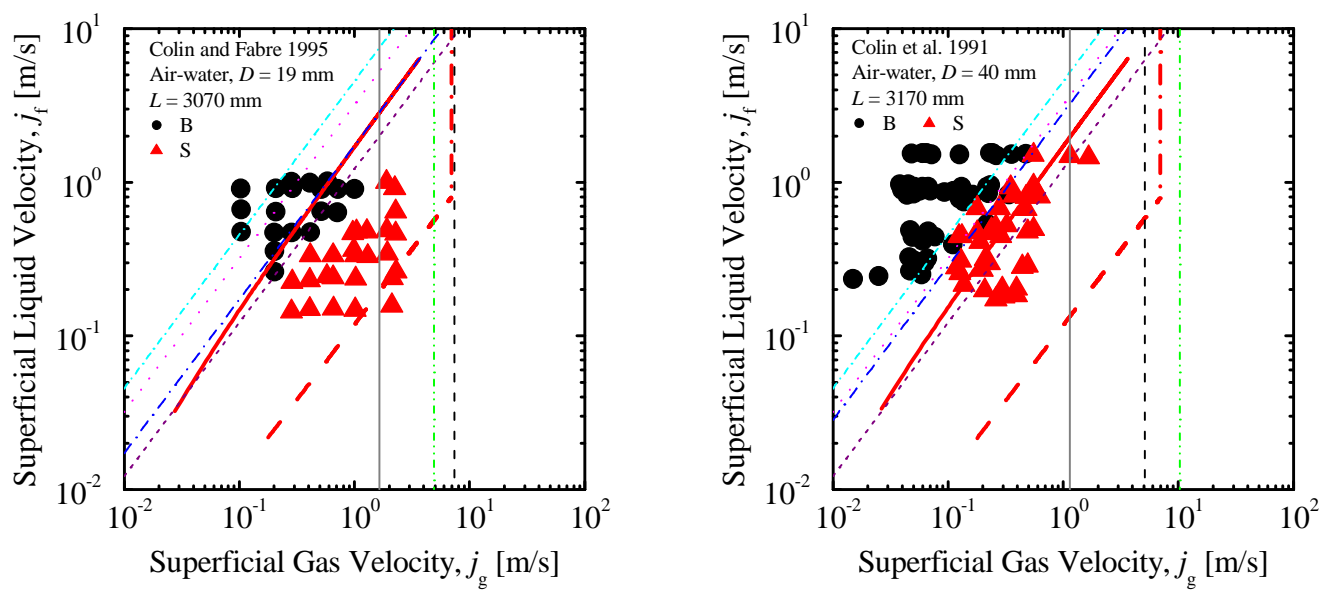

c

d 
Fig. 6
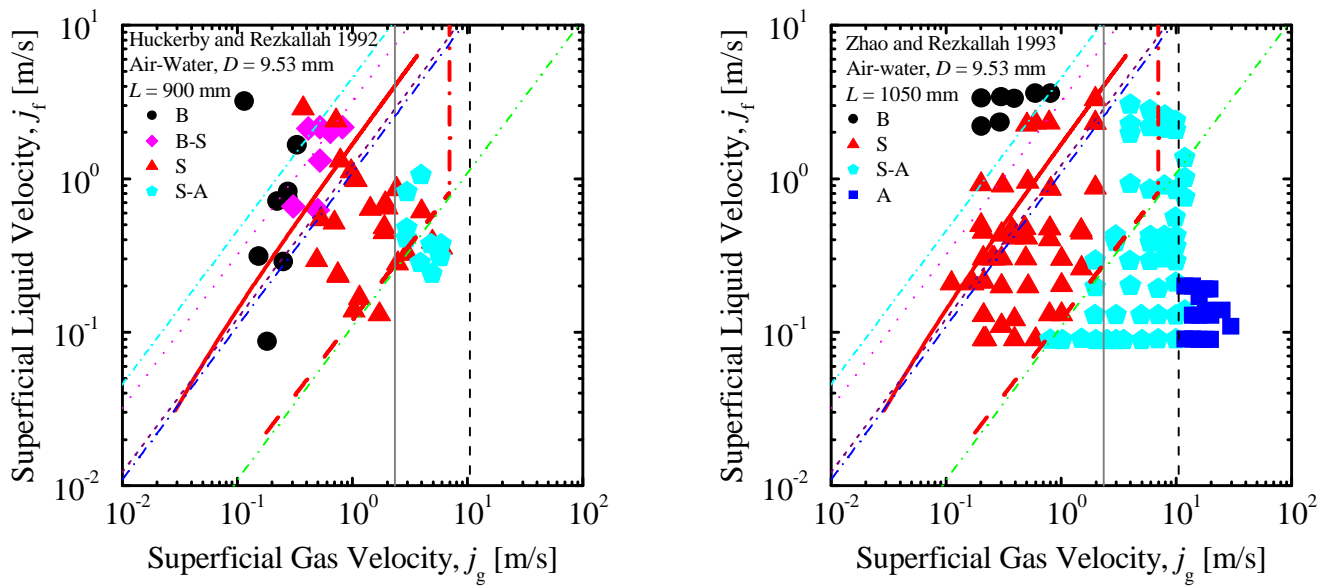

a

b
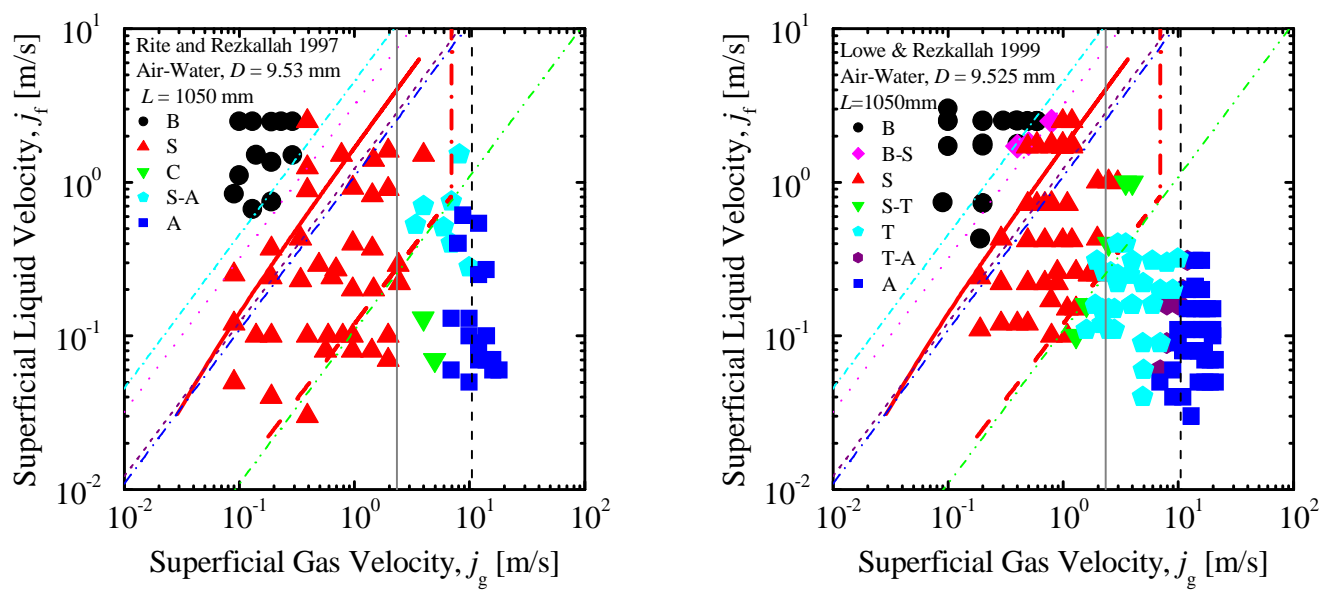

c

d 
Fig. 7
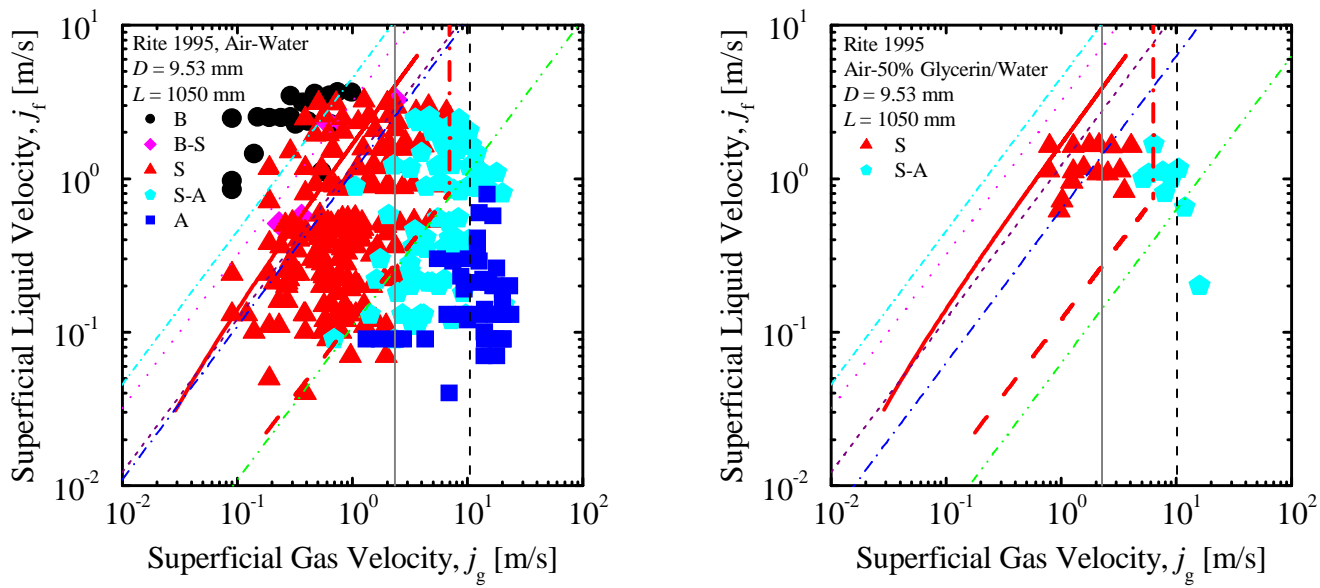

a

b
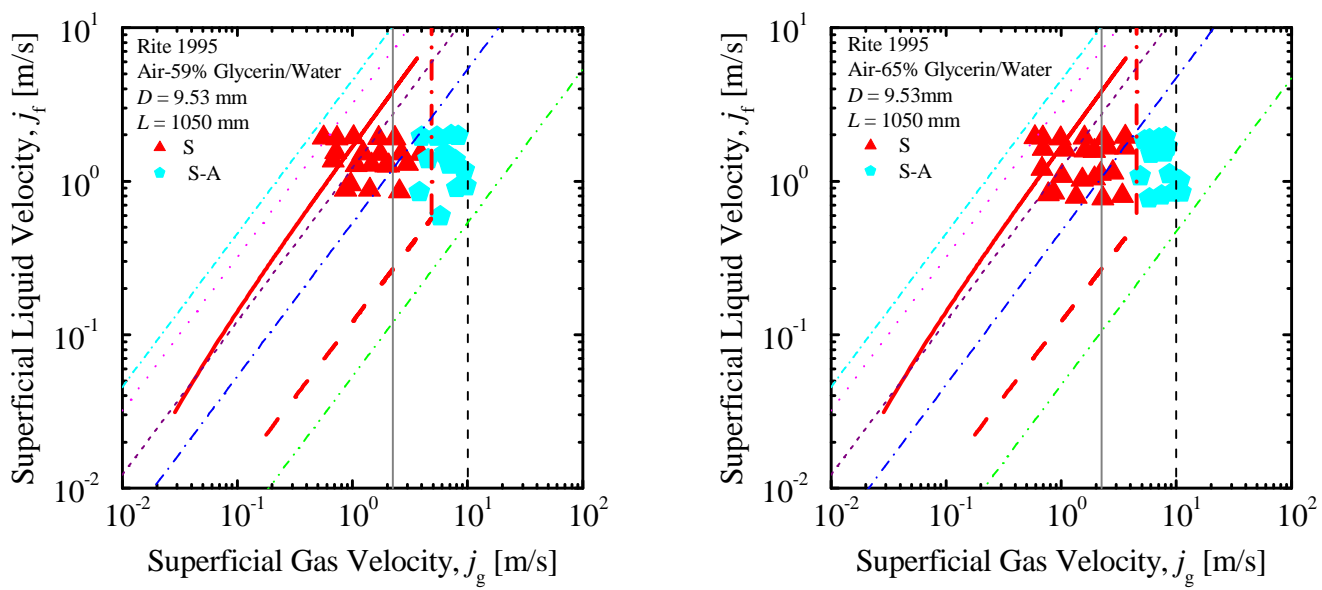

c

d 
Fig. 8
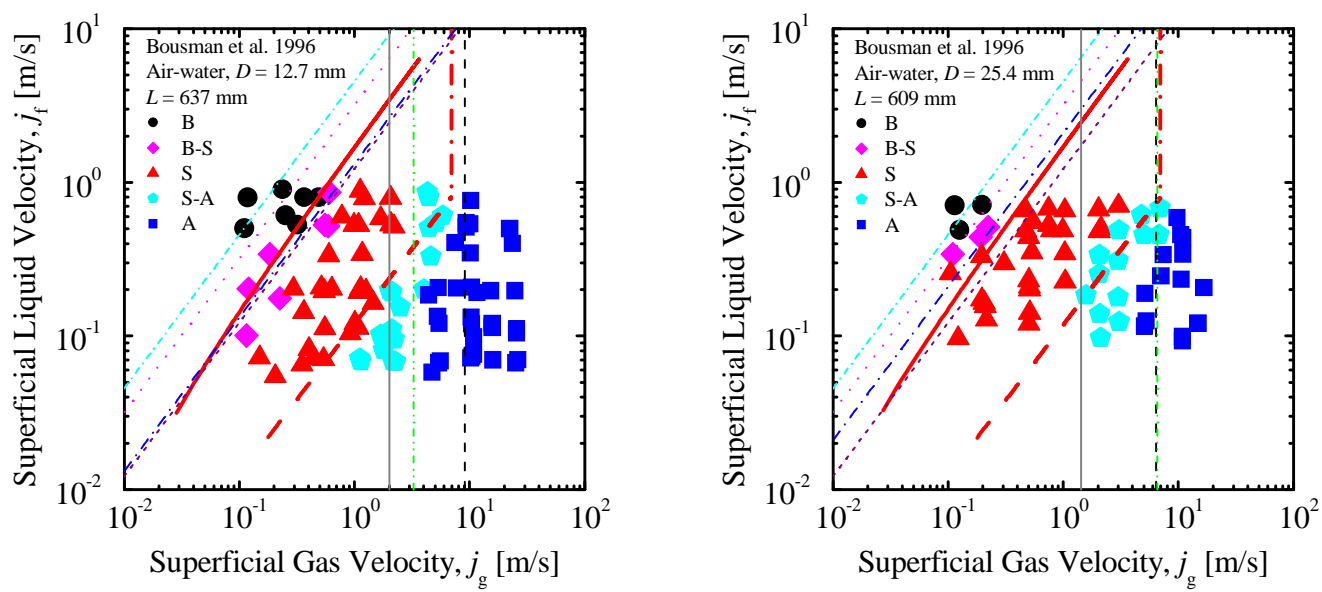

a

b
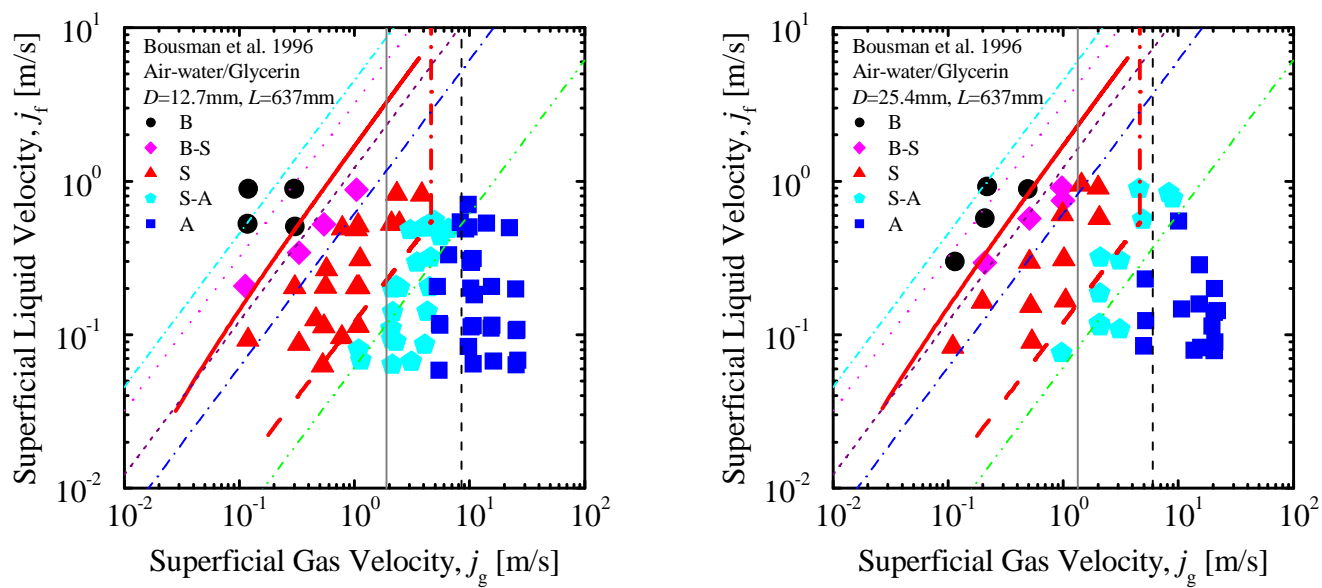

c

d
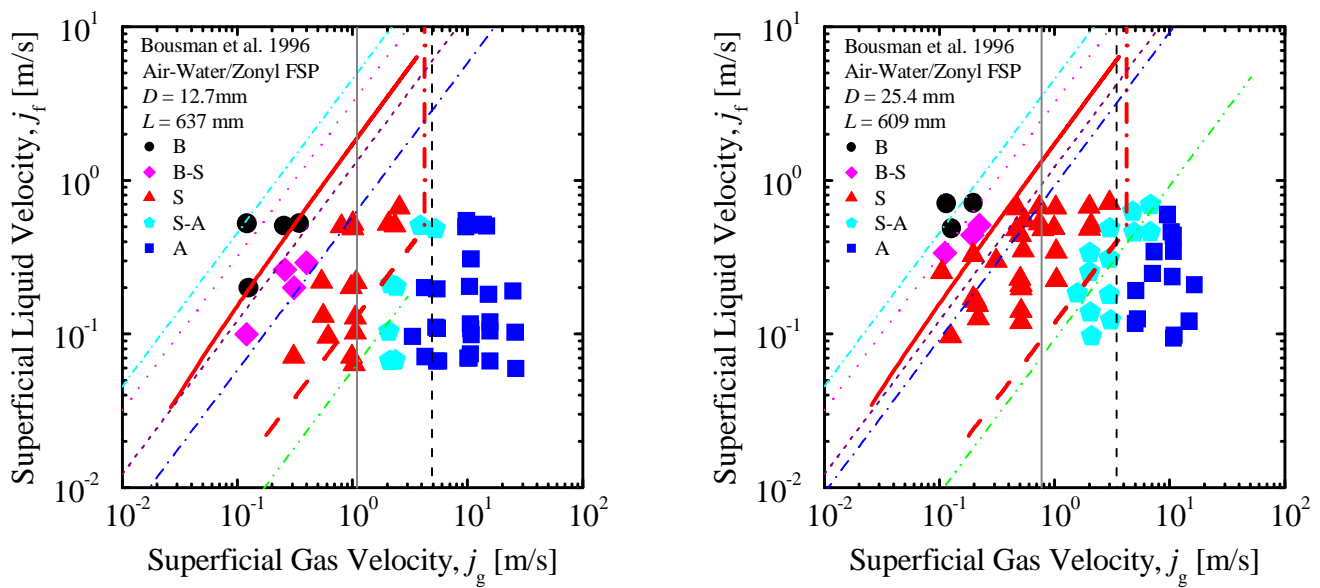
Fig. 9
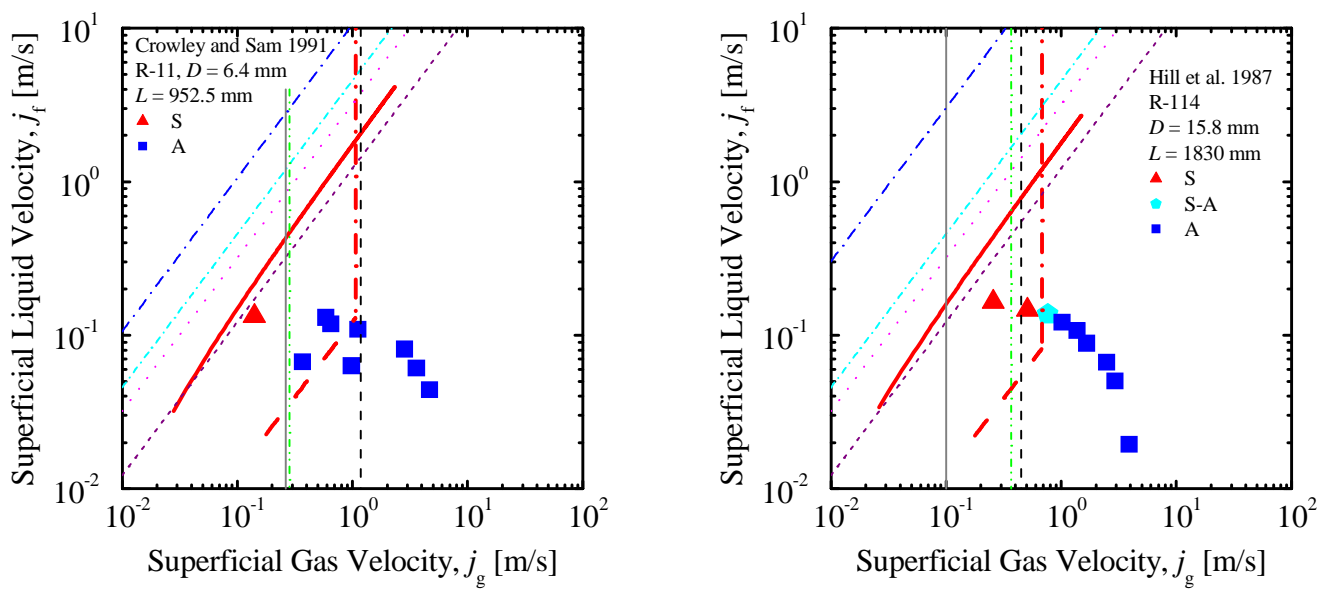

a

b
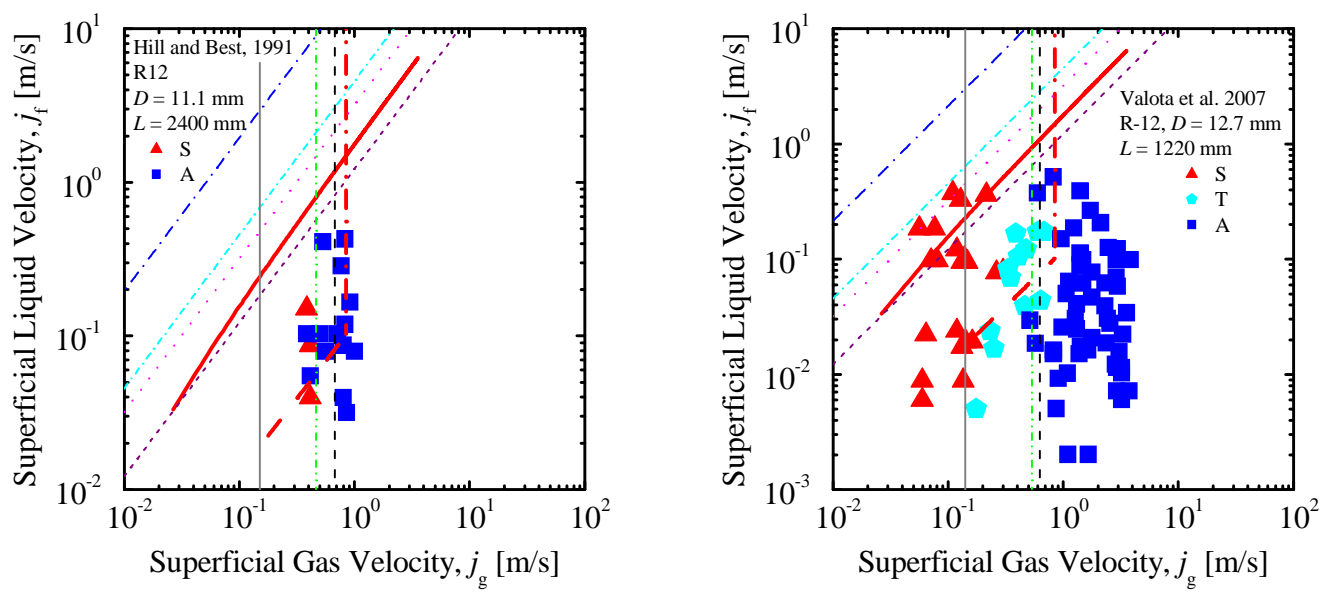

c

d 
Fig. 10

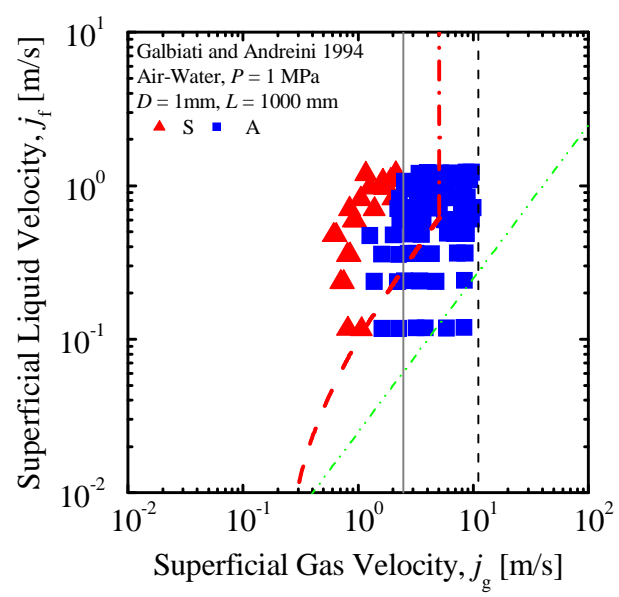

a

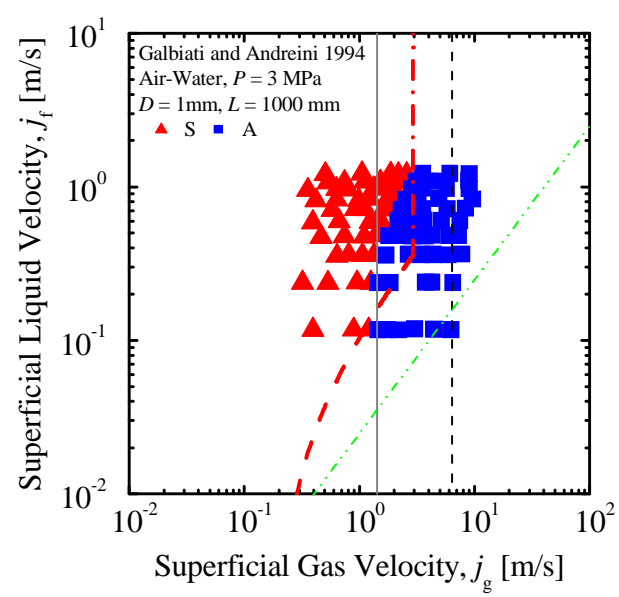

b

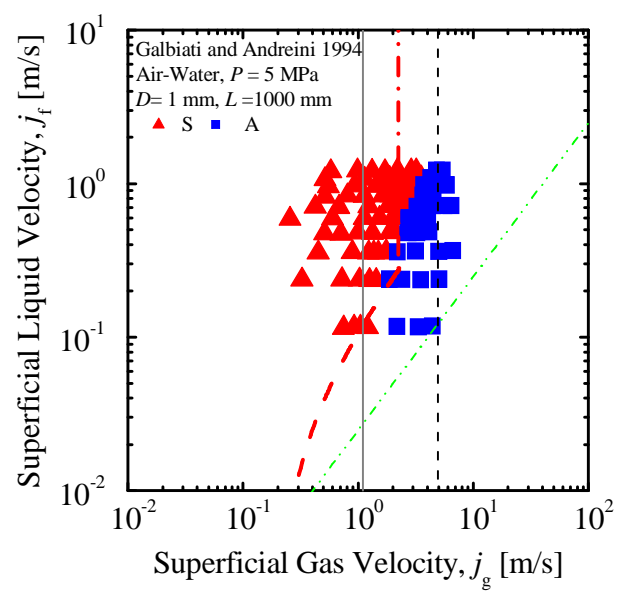

c 
Fig. 11

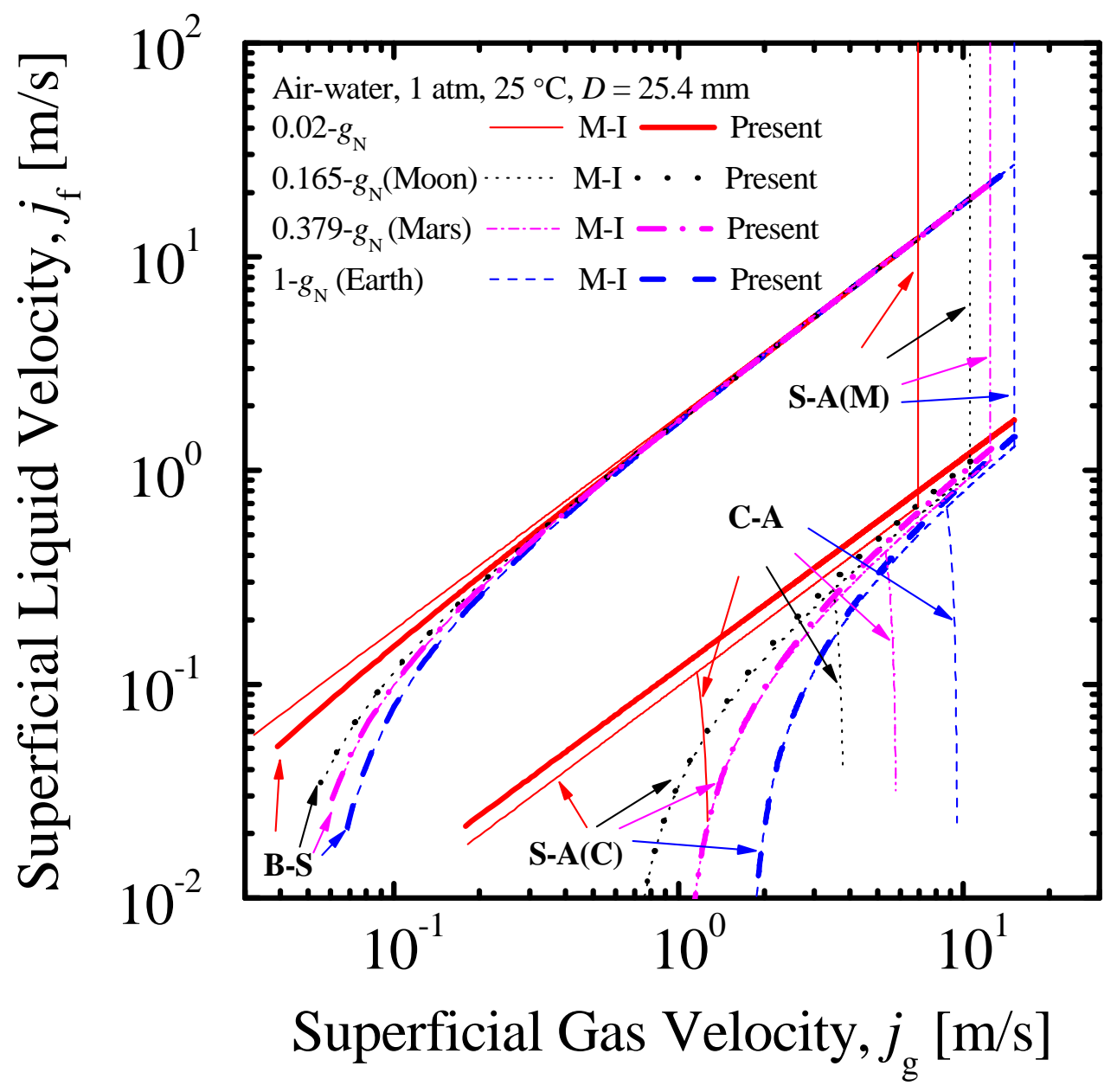

